Running head: Union Commitment Profiles

\title{
Investigating the Dimensionality and Stability of Union Commitment Profiles Over a 10- Year Period: A Latent Transition Analysis
}

Alexandre J.S. Morin*, Substantive Methodological Synergy Research Laboratory, Department of Psychology, Concordia University, Montreal, Canada

Daniel G. Gallagher*, College of Business, James Madison University, U.S.A.

John P. Meyer, Department of Psychology, The University of Western Ontario, Canada, and Curtin Business School, Curtin University, Australia

David Litalien, Faculté des sciences de l'éducation, Université Laval, Canada

Paul F. Clark, School of Labor and Employment Relations, Pennsylvania State University, U.S.A.

* The first two authors (A.J.S.M. \& D.G.G.) contributed equally to this article and their order was determined at random: both should thus be considered first authors.

This is the prepublication version of the following manuscript:

Morin, A.J.S., Gallagher, D.G., Meyer, J.P., Litalien, D., \& Clark, P.F. (in press). Investigating the dimensionality and stability of union commitment profiles over a 10-year period: A latent transition analysis. Industrial \& Labor Relations (ILR) Review. DOI: $10.1177 / 0019793919883815$

(C) 2019. This paper is not the copy of record and may not exactly replicate the authoritative document published in ILR Review.

\begin{abstract}
We adopt a person-centered approach to the investigation of the dimensionality of the union commitment construct, capitalizing on a 10-year longitudinal study of 637 union members in their first year of employment measured again one and 10 years later. Our results revealed four distinct profiles of union commitment, presenting a stable structure over time. These profiles demonstrated consistency in commitment level across the three most common union commitment dimensions, thus questioning the necessity of adopting a multidimensional approach. Our results showed that union members became more similar to other members of their profiles over time, and that union commitment became slightly less extreme as union tenure increased. Finally, our results showed that union commitment profiles predicted union participation in accordance with our expectations, and suggested that endorsing positive attitudes toward unions and their instrumentality were a stronger predictor of profile membership than satisfaction with the actions of their own union.
\end{abstract}

Key words: union commitment, profiles, latent transition analyses, longitudinal stability, union attitudes, union satisfaction, union participation. 


\section{Introduction}

Although not the first to investigate the nature and implications of union commitment (UC), the seminal work by Gordon, Philpot, Burt, Thompson and Spiller (1980) is widely recognized has having energized this field of research through their conceptualization of $\mathrm{UC}$ as a multidimensional construct. Much of the research conducted subsequently in this area was fueled by debates over whether UC should indeed be treated as a multi-dimensional construct and, if so, what dimensions were encompassed by this construct. Various options have been proposed, but arguably the most widely accepted multidimensional option included one attitudinal component - union loyalty (UCL) - and two behavioral components - responsibility to the union (UCR) and willingness to work for the union (UCWW). While conceptually distinct, measures of these components have consistently been found to be moderately to highly correlated with one another, and to relate similarly to measures of theoretical antecedents and outcomes. The latter findings have contributed to calls for a unidimensional approach that, in addition to being more parsimonious, allows for the use of shorter measures. Even here, however, there is disagreement as to whether such a measure should include items from each of the components, one of the components (typically UCL), or a re-conceptualized construct adapted from the broader commitment literature (i.e., affective commitment).

The dimensionality and measurement of the UC construct are important issues because they set the stage for all research pertaining to the development and consequences of UC which are, in turn, crucial for union management. To date, this dimensionality question has been addressed using a variablecentered research strategy that involves examining correlations among UC components along with regression-based analyses to investigate their independent or combined relations with other variables. As noted above, the correlations between the components tend to be quite strong, and the relations with other variables quite similar. An assumption underlying the variable-centered approach is that the parameters (e.g., correlations or regressions) hold for the population at large. Recent applications of an alternative person-centered approach in the broader commitment literature (and indeed in the organizational sciences in general) have demonstrated that such assumptions do not always hold. To the contrary, even variables that are quite strongly correlated in the population as a whole, can combine differently across subpopulations. This raises the possibility that UCL might combine with strong UCR and/or UCWW for some union members, but not for others. That is, some members might be more inclined to demonstrate their loyalty with supportive action than are others. In person-centered terminology, these subpopulations would be considered to have different commitment 'profiles.' In addition, observing profiles characterized by such a differentiated configuration of UC components would support the practical value of distinguishing among these components, despite their high correlations. These profiles can be detected using analytic techniques such as latent profile analysis (LPA). Once identified, subsequent analyses can be conducted to investigate how these profiles relate to various theoretical antecedents and outcomes. One might find, for example, that UCL, UCD, UCWW are more similar in strength (high, moderate, or low) among members with moderate tenure than with short or long tenure. Among the latter, some might have a strong UCL but weaker UCD or UCWW. Members with such a profile might not feel sufficiently prepared to get actively involved, or might feel that it is time to step aside to let others take over, respectively. Such a pattern reflects non-linearity in the relations among the components, and in their relations with other variables, that can be difficult, if not impossible, to detect in variable-centered research.

The vast majority of UC research has been cross-sectional in nature, and therefore precludes investigation of how UC changes over time, and how these changes relate to other variables. Although there are variable-centered strategies for the analysis of longitudinal data, they also involve the assumption that the results would apply to the population as a whole. In contrast, person-centered analytic techniques such as latent transition analyses (LTA) allow for the possibility that the components of UC combine differently, and relate differently to other variables, both within and across time. The use of LTA permits the investigation of stability versus change in the configurations of UC components, the composition of the subpopulations, and the relations between the profiles and various antecedents and outcomes over time. This can have important implications for how UC is managed as members' tenure in the union increases. That is, do the same subpopulations exist, do they increase or decrease in size, do they behave in the same ways, and, importantly, are they influenced by the same or different personal and situational factors? 
In the present research, we take a person-centered approach to the investigation of UC data collected on three occasions, including at entry and one and 10 years later. We use LPA at each time point to determine whether there are subpopulations with distinct combinations of UCL, UCD and UCWW, followed by analyses to determine how these profiles related to several antecedent (union attitudes, instrumentality and satisfaction) and outcome (citizenship behavior) variables. We then use LTA along with recently developed analytic techniques to investigate the stability of the profiles, profile membership, and relations between the profiles and the covariates (antecedents and outcomes). Because this person-centered analysis allows for the detection of non-linearity in relations among UC components, it provides a particularly strong test of the dimensionality of the construct (i.e., whether the strong relations among UCL. UCD, and UCWW hold consistently or vary across subpopulations). Our approach also allows for the detection of changes in UC, its antecedents, and its consequences, over time, all of which have important implications for union management.

\section{Union Commitment and the Dimensionality Debate}

Following preliminary work on union commitment and loyalty (e.g., Purcell 1953; Stagner 1954), and stimulated by theory and research pertaining to organizational commitment (Porter, Crampton, and Smith, 1976), Gordon et al. (1980) proposed that UC is best conceptualized as a multidimensional construct. The four dimensions included: (1) Union Loyalty (UCL) - a sense of pride in the union and awareness of its instrumentality; (2) Responsibility to the Union (UCR) - a commitment to fulfilling day-to-day membership duties; (3) Willingness to Work for the Union (UCWW) - a willingness to work for and provide functional support to the union; and (4) Belief in Unionism (UCBelief) - positive attitudes to the goals and broader objectives of unionism. From an initial pool of 48 items, Gordon and his colleagues also provided empirical support for both a 30-item (Gordon et al., 1980) and a 28-item (Ladd, Gordon, Beauvais, and Morgan 1982) measure of UC. The theory, including propositions regarding the development and outcomes of UC, along with the provision of measures, stimulated a large body of subsequent research (Horsman, Gallagher, and Kelloway, 2016).

In many of the early follow-up investigations involving various adaptations of Gordon et al.'s measures, UC was treated as a four-dimensional construct, often without evaluation (e.g., Fields and Thacker 1992; Hoell 2004; Mellor 1992). Among investigators who evaluated the factor structure of the measures, some confirmed the four-factor structure (Iverson and Kuruvilla 1995; Kuruvila and Iverson 1993; Shore, Tetrick, Sinclair, and Newton 1994; Tetrick, Thacker, and Fields, 1989; Thacker, Fields, and Tetrick 1989), whereas others did not (Friedman and Harvey, 1986; Fullagar, 1986; Fullagar and Barling, 1991; Klandermans, 1989). Friedman and Harvey (1986) re-analyzed Gordon et al.'s data and concluded that a 20-item two-factor solution focusing on "union attitudes" and "pro-union behavioral intentions" provided a simpler solution. Klandermans (1989) conducted a replication study using the Gordon et al. measure in a Dutch sample and found support for a two-factor solution representing UCL and UCWW. In a study of South African unionized workers, Fullagar (1986) found that the 28-item version of Gordon et al.'s measure followed a five-factor solution, with only the "union loyalty" (i.e., UCL) and "responsibility to the union" (i.e., UCR) factors resembling those proposed by Gordon et al. Fullagar and Barling (1991) reported similar findings in a study conducted in Canada. Still other researchers, based on evidence that the UCL factor generally accounted for most of the variance in UC and was most stable across studies, chose to treat UC as a unidimensional construct using UCL items only (Fullagar and Barling 1989; Tan and Ayree 2002). Finally, some researchers adopted a measure of affective commitment (AC: Meyer and Allen, 1997) from the organizational commitment literature to measure UC (Redman and Snape 2005; Snape, Redman, and Gould-Williams 2014).

In an effort to address the inconsistency across studies with regard to the factor structure on UC, Kelloway, Catano and Southwell (1992) developed a parsimonious 13-item measure reflecting three dimensions: union loyalty (UCL), responsibility to the union (UCR), and willingness to work for the union (UCWW). This measure has since been applied in several studies (Catano, Pond, and Kelloway 2001; Fullagar, Gallagher, Gordon, and Clark 1995; Fullagar, Gallagher, Clark, and Carroll 2004; Hammer, Bayazit, and Wazeter 2009; Kelloway and Barling 1993) and the three-factor structure has generally been supported. However, the factors have consistently been found to be highly correlated, thereby raising questions about the utility of treating the construct as multidimensional. Indeed, this evidence, in combination with demands for shorter measures for use in applied research, has contributed to the popularity of the unidimensional measures described above. 
In sum, there is still debate about the dimensionality of UC, with the Kelloway et al. (1992) threedimensional measure being widely adopted by those taking a multi-dimensional perspective, and the UCL-only or AC-based measures being commonly used by those seeking a short unidimensional measure. Thus, there are two related issues at play here. The first is whether there is sufficient evidence to justify the treatment of UC as a multidimensional construct, and the second is whether UCL items alone, or a global AC-like construct, are able to fully capture the construct. To date, research addressing these issues has been variable-centered. In the present study, we take a person-centered approach, the advantages of which are described below following discussion of the antecedents and consequences of UC.

\section{Antecedents and Outcomes of Union Commitment}

Looking beyond the dimensionality issue, researchers have also been particularly interested in the development (antecedents) and consequences (outcomes) of workers' union commitment. In a metaanalytic review of 80 independent samples from 59 separate studies, Bamberger, Kluger, and Suchard (1999) found that workers' attitudes toward unions in general (i.e., a pro-union ideology) and beliefs about union instrumentality were particularly strong predictors of UC. These findings were confirmed in a more recent meta-analysis by Monnot, Wagner, and Beehr (2011). There is also considerable evidence for a positive relation between workers' UC and their satisfaction with the local union (Fullagar, McCoy, and Shull 1992; Iverson and Kuruvilla 1995; Kelloway and Barling 1993; Sverke and Sjöberg 1994). Further evidence suggests that workers are more satisfied with, and committed to, the union when it is seen as responsive to membership input and as offering opportunities for involvement (Magenau, Martin, and Peterson 1988; Morishima 1995; Snape et al. 2000; Sverke and Sjöberg 1994).

Thus, UC appears to be predicted both by general beliefs about the effectiveness of union in general in bringing about positive changes in working conditions, and satisfaction with the way workers are treated by their own union. In turn, unions benefit from strong UC in terms of greater involvement and participation on the part of workers. Indeed, in their meta-analysis, Monnot et al (2001) found that UC was a key antecedent of union participation (also see Fullagar et al., 2014).

It is important to note that research examining the antecedents and outcomes of UC has been conducted using a variety of unidimensional and multidimensional measures of UC. Therefore, it is difficult to determine whether the relations are similar or different across dimensions of UC and/or whether the relevant variance can be explained adequately using a unidimensional measure (i.e., UCL only, or union AC). Our person-centered investigation will allow us to determine how the antecedents and outcomes relate to varying configurations of the underlying UC dimensions, and whether these relations are best explained by one or a combination of the dimensions. Also, the bulk of the research evidence regarding the antecedents and outcomes of UC has been cross-sectional, thereby precluding direct testing of the longitudinal stability of the associations between union commitment, antecedents, and outcomes. Therefore, a second major objective of the present study was to examine how UC relates to key antecedents and outcomes over a 10-year period, beginning at union entry.

\section{The Present Study}

The present study addresses the dimensionality of UC, and the relations between UC and some of its key antecedents and outcomes over a 10-year period, using the measure developed by Kelloway et al. (1992). In contrast to previous variable-centered research, we employ a person-centered approach. Unlike the variable-centered approach that assumes that all individuals from a sample are drawn from a single population, and that a single set of averaged parameters can be estimated, the person-centered approach considers the possibility that the sample might reflect multiple subpopulations characterized by different sets of parameters. The objective, therefore, is to identify subpopulations presenting different configurations (or profiles) with regard to a system of variables. In this case, we use latent profile analysis (LPA) to identify subpopulations of unionized workers with varying configurations of UCL, UCR, and UCWW. By examining the profiles characterizing these subpopulations, we can determine whether the configurations are qualitatively (i.e., shape and dispersion) and/or quantitatively (i.e., level only) different (Meyer \& Morin, 2016; Morin, 2016). If the profiles are qualitatively different, it suggests that, despite their typically strong correlations, the subscales can be considered to measure meaningfully distinct constructs. For example, it might be possible for some individual with strong UCL to also have strong UCR and/or UCWW, whereas others with strong UCL would have moderate or weak UCR and/or UCWW. However, if the only differences are quantitative, it suggests that UC, despite 
variable-centered evidence suggesting the presence of distinct dimensions, is best considered to be unidimensional from a practical perspective (Gillet, Morin, Cougeot and Gagné, 2017). We can also determine from the shape of the profile whether differences across profiles are best captured by considering one, two, or all three dimensions. Because this is the first application of LPA to investigate the dimensionality of $\mathrm{UC}$, and because previous variable-centered studies have produced mixed results, it is premature to offer specific hypotheses about the number and nature of the profiles likely to emerge. Therefore, we elected to focus on a more exploratory set of research questions.

Research Question 1 (RQ1). How many profiles will be required to present a comprehensive picture of members' multidimensional commitment to their union?

Research Question 2 (RQ2). Will the identified multidimensional union commitment profiles differ from one another qualitatively (shape), thus supporting the added value of a multidimensional conception of union commitment, or quantitatively (level), thus supporting a more global unidimensional representation of union commitment?

By using longitudinal data in this study, we are also able to investigate whether the profile structure of UC remains consistent or changes over time. In either case, we can also use latent transition analyses to determine whether individuals transition from one profile to another over time. Prior variable-centered research suggests that levels of union commitment tend to be relatively stable over time when the various subscales are considered separately (e.g., Tetrick et al. 1989). However, this approach does not allow for the possibility that there may be changes over time in the ways that the dimensions of UC combine (within-sample stability), and that the configuration will remain stable for some individuals but change for others (within-individual stability). For example, individuals with strong UCL might only be willing to take responsibility (UCR) or work for the union (UCWW) as they gain experience. Similarly, for individuals with weak UC at entry, UCL might strengthen more quickly with experience than will UCR and/or UCC; the latter might only increase once UCL achieves a critical state. These are only two of the many possible patterns of change that can be detected using a personcentered approach. Therefore, in the absence of any clear basis for prediction, we posed a set of research questions rather than offering specific hypotheses.

Research Question 3 (RQ3). To what extent will the extracted profiles of union commitment remain stable (within-sample stability) over a 10 year period?

Research Question 4 (RQ4). To what extent will individual members' profiles of union commitment remain stable (within-person stability) over a 10-year period?

We will examine stability using procedures applied by Kam, Morin, Meyer and Topolnytsky (2016), and expanded by Morin, Meyer, Creusier, and Biétry (2016; Morin and Wang 2016). More specifically, we will examine within-sample consistency by comparing a series of nested model using LPA. Within-person stability will be examined using LTA. The specific procedures used to conduct these tests will be elaborated in the Method section.

Our final objective was to examine how some of the key antecedents (union attitudes, union instrumentality, and union satisfaction) and outcomes of UC (union participation) relate within and across time with UC profiles. This investigation serves two important purposes. First, it allows us to determine how these antecedents and outcomes relate within and across time to combinations of UCL, UCR, and UCWW. In previous variable-centered research, relations were examined only for the individual subscales or a composite measure of UC. Second, demonstrating that profiles relate in meaningful ways to other theory-relevant variables is helpful in establishing the construct validity of the observed profiles (Meyer \& Morin, 2016). Based on previous research (Bamberger et al. 1999; Horsman et al. 2016; Monnot et al. 2010; Snape et al. 2000), we expect to find significant relations between the covariates and profile membership, suggesting that more positive attitudes, higher instrumentality, and higher satisfaction should predict a higher likelihood of membership into the profiles characterized by the highest levels of union commitment, which should themselves be accompanied by higher levels of union participation. However, given the lack of specific hypotheses regarding the expected nature of the profiles, we leave these associations as an open research question. Furthermore, Morin et al.'s (2016) framework for tests of profile similarity can also be extended to test the similarity of associations between profiles and predictors or outcomes across time waves, a critical issue which will also be investigated in the present study.

Research Question 5 (RQ5). To what extent will members' levels of union attitudes, union instrumentality, and union satisfaction predict their likelihood of membership into the various 
union commitment profiles?

Research Question 6 (RQ6). To what extent will members' union commitment profiles be associated with their levels of union participation?

Research Question 7 (RQ7). To what extent will the associations between members' union commitment profiles, their antecedents (union attitudes, union instrumentality, and union satisfaction) and their outcomes (union participation) remain stable over a 10-year period?

\section{Sample and Procedures}

Method

The participants in this study were members of the National Association of Letter Carriers' (NALC) employed by the United States Postal Service (USPS). The NALC has a voluntary and active membership of over 180,000 mail carriers with approximately 2,500 union locals or branches throughout the United States. NALC records indicate that approximately $90-95 \%$ of eligible members elected to join the union. Possible explanations for this high rate of participation are that membership is required for enrollment in the attractive NALC Health Benefit Plan, the NALC has a particularly strong orientation program, and there is a high degree of homogeneity within the membership (i.e., only letter carriers). The initial objective of the study was to provide NALC assistance in evaluating "new member" orientation programs. The NALC was able to identify a sample of 2,000 members who had joined the union within the prior 12 months leading up to the initial survey.

In the first wave (T1) of the study (for details, see Fullagar, Clark, Gallagher, and Gordon 1994), questionnaires were mailed to all 2,000 new NALC members. A total of 637 (32\%) completed surveys were returned. Consistent with the goal of focusing on new members, the average union tenure was 5.38 months. As originally envisioned in the research design, a follow-up survey (T2) was sent 12 months later to all members who had responded to the first survey (for details, see Fullagar et al. 1995). A total of $342(54 \%)$ responded to the second survey. The average years of union membership for T2 respondents was 15.02 months. With support from the NALC, a subsequent survey was designed to examine longer term implications among all members who had participated in both T1 and T2 almost 11 years (T3) after the initial T1 survey (for details, see Fullagar et al. 2004). Based upon employment records it was discovered that of the original T1 respondents only 454 were still employed as letter carriers by the USPS. Surveys were sent by mail to the population of T1 and T2 participants and a total of 195 questionnaires were returned to the researchers.

\section{Measures}

Union Commitment. Union commitment was measured at all time waves (T1, T2, and T3) using Kelloway et al.'s (1992) 13-item union commitment scale. This scale assesses three dimensions of union commitment: union loyalty (UCL, six items, e.g., I feel a sense of pride in being a part of the union); responsibility to the union (UCR, four items, e.g., It is the duty of every member to keep their ears open for information that might be useful to the union); and willingness to work for the union (UCWW, three items, e.g., If asked I would serve on a committee for the union). Each item was measured on a fivepoint scale ranging from ( $1=$ strongly disagree to $5=$ strongly agree $)$.

Union Attitudes and Instrumentality. Attitudes toward unions and perceptions of union instrumentality were assessed at T1, T2, and T3 using items drawn from investigations of pro-union voting and joining (e.g., Deshpande and Fiorito 1989; Getman, Goldberg, and Herman 1976; McShane 1986). A first subscale consists of five items capturing the degree to which individuals agree that unions meet the stereotype of being undemocratic and economically counterproductive (e.g., unions stifle individual initiative, unions are more interested in fighting change than trying to bring about change). These items were recoded to reflect positive union attitudes. A second subscale assesses the extent to which individual members broadly perceive labor unions as a force for improving the lives of working people. This measure of union instrumentality consisted of four items (e.g., unions work to get legislation that helps all working people, unions improve the wages and working conditions of workers). Both measures were scored on a five-point scale indicating respondent strength of agreement with each stated item ( $1=$ strongly disagree to $5=$ strongly agree $)$.

Union Satisfaction. Participants were asked at T1, T2, and T3 to evaluate their perceptions of the performance of the NALC. Based upon the work of Quinn and Staines (1978) and Fiorito, Gallagher, and Fukami (1988) this measure included two four-item subscales labeled union satisfaction - formal aspects and union satisfaction - union-member relationships. The first subscale assesses satisfaction toward the NALC's performance at improving the economic terms and conditions of employment for 
letter carriers (e.g., How good a job has the NALC done in getting better wages for members, ... improving job security). The second subscale pertains to perceptions of the favorability of the relationship between the union leaders and individual members (e.g., ... keeping member's informed, $\ldots$ giving member's a voice in union matters, ... listening to concerns, and ... providing support when needed). Each item was measured on a five-point scale ranging from ( $1=$ strongly disagree to $5=$ strongly agree).

Union Participation. Drawing Skarlicki and Latham (1996) and more recent investigations of union commitment (e.g., Chan, Snape, and Redman 2011; Snape, et al. 2014; Tan and Ayree 2002) union participation was operationalized as union citizenship behaviors (UCB) and assessed at T2 and T3. The first four-item subscale pertains to membership participation in terms of individual actions which were focused on "interpersonal helping" (UCB-I; e.g., helped a fellow member prepare a grievance, showed another member how the union could assist them with a problem). The second 10item subscale assesses membership participation in terms of individual actions which were supportive of the union as an "organization" (UCB-O; e.g., attended and spoke up at a union meeting, participated in a branch (local) social or recreational activity, encouraged other members to support the union on an issue, offered assistance to the union in resolving a union-related problems, etc.). All items were rated dichotomously $(0,1)$ as a function of respondents' participation during the prior 12 months.

\section{Analyses}

Confirmatory factor analyses (CFA) were first estimated to verify the adequacy of the measurement models underlying the constructs assessed in this study and their measurement invariance across the three time waves. These models supported the adequacy of the a priori models, and their longitudinal invariance, but also revealed high level of within-time correlations (corrected for measurement errors) between the union commitment dimensions ( $r=.63$ to $.83, M_{r}=.74$ : see Table 1$)$. From these models, composite reliability was calculated with McDonald's (1970) omega $(\omega)$ coefficients, which were relatively high and satisfactory for the commitment ( $\omega=0.776$ to 0.925 ), predictors ( $\omega=0.710$ to 0.894$)$, and outcomes ( $\omega=0.884$ to 0.890$)$ measures. Rather than using scale score to estimate the profiles, factor scores from these preliminary models were used as inputs in the main analyses. To ensure comparability in the measures across time points, these factors scores were saved from longitudinally invariant measurement models (Millsap 2011). Factor scores provide a way to partially control for the unreliability of participants' ratings by giving more weight to items presenting lower levels of measurement error (Skrondal and Laake 2001) and to preserve the nature of the underlying measurement structure (e.g., invariance) better than scale scores (for a more extensive discussion of the advantages of factor scores in person-centered analyses, see Morin, Meyer, et al. (2016) or Morin, Boudrias et al. (2016 2017). Details on these measurement models, longitudinal invariance, and missing data strategies, are reported in the online supplements. Table 1 presents the correlations and composite reliability for all factors scores.

Latent Profile and Latent Transition Analyses. We first estimated LPA on the union commitment factors at each time points separately (Muthén 2002) to verify whether the same number of profiles would be extracted. These LPA provided further evidence that the results remained unchanged by the missing data strategy used in this study. At each time point, we examined solutions including one to eight profiles. The mean and variance of the profile indicators were freely estimated in all profiles (Peugh and Fan 2013).

To determine the number of latent profiles in the data, the theoretical meaning and statistical adequacy of the solution should be taken into account, as well as a variety of statistical indicators (Marsh, Lüdtke, Trautwein, and Morin 2009; Muthén 2003): (i) The Akaïke information criterion (AIC), (ii) the consistent AIC (CAIC), (iii) the Bayesian information criterion (BIC), (iv) the sample-size adjusted BIC (ABIC), (v) the adjusted Lo, Mendel and Rubin's (2001) likelihood ratio test; and (vi) the bootstrap likelihood ratio test (BLRT). A lower value on the AIC, CAIC, BIC and ABIC suggests a better-fitting model. A significant $p$ value for the aLMR and BLRT indicates that additional profile contributes to the solution. Simulation studies indicate that the CAIC, BIC, ABIC, and BLRT are particularly effective (Peugh and Fan 2013; Tein, Coxe, and Cham 2013; Tofighi and Enders 2008). However, with sufficiently large sample sizes, these indicators may keep on suggesting the addition of profiles (Marsh et al. 2009). In these cases, information criteria should be graphically presented through "elbow plots" (Morin, Maïano, et al. 2011). In these plots, the point after which the slope flattens out indicates the optimal number of profiles. Finally, the entropy should not be used to select the optimal number of profiles, but provides a useful summary of the classification accuracy, varying from 0 to 1 , with higher 
values indicating more accuracy.

Once the optimal number of profiles has been selected at each time point, the three time-specific models were combined into a longitudinal LPA. From this model, we proceeded to tests of profile similarity across time points using a strategy developed by Morin, Meyer et al. (2016) and optimized by Morin and Litalien (2017) for longitudinal comparisons. The first step in the sequence examines whether the same number of profiles can be identified across time points (i.e., their configural similarity) and corresponds to the previously described time-specific LPA In the second step, the "structural similarity" of the profiles is tested by including equality constraints across time point on the means of the profile indicators. The third step tests the "dispersion similarity" of the profiles by including equality constraints across time point on the variances of the profile indicators. The fourth step tests the "distributional similarity" of the profiles by constraining their size to equality across time points.

The most similar model from the previous sequence was then converted to a longitudinal LTA (Collins and Lanza 2010) to investigate within-person stability and change in profile membership (Morin and Litalien 2017). This sequence was then extended to tests of "predictive" and "explanatory" similarity to test whether the associations between the profiles, their predictors and their outcomes remained the same over time. The relative fit of these models can be compared using the aforementioned information criteria, and Morin, Meyer et al. (2016) suggest that at least two indices out of the CAIC, $\mathrm{BIC}$, and ABIC should be lower for the model including added constraints for the hypothesis of profile similarity to be supported.

All models were estimated using the robust maximum likelihood estimator (MLR) available in Mplus 7.2 (Muthén, and Muthén 2014). All LPA were estimated using 3000 random sets of start values, 100 iterations, and the 100 best solutions retained for final stage optimization (Hipp and Bauer 2006). These values were increased to 10000,1000 , and 500 for the longitudinal models. Because of the strategy used to generate the factor scores, there were no missing data in these models, which helped to maximize sample size (see online supplements for further discussions about missing data).

Predictors and Outcomes of Profile Membership. Multinomial logistic regressions were conducted to test the relations between the likelihood of profile membership and a series of demographic controls and predictors. In these analyses, we first assessed the need to incorporate demographic variables as possible controls in subsequent analyses (age, sex, education level, and union tenure). In these analyses, the demographic controls were allowed to predict the profiles estimated at all time points. Four alternative models were contrasted (e.g., Ciarrochi, Morin, Sahdra, Litalien, and Parker 2017; Gillet et al. 2018). First, we considered a null effects model in which the relations between the demographics and the profiles were constrained to be zero. Second, the relations between the demographics and the profiles were freely estimated across time points, predictions of the profiles estimated at a specific time point were allowed to vary across the profiles estimated at the previous time point. Essentially, this model provides a direct test of the effects of the demographic variables on the profile transitions (i.e., on the likelihood of transitioning into a specific profile at the next time point based on profile membership at the prior time point). Third, predictions were freely estimated across time, but not profiles. In this model, the demographic controls are not allowed to predict the profile transitions themselves, but their effects are allowed to change over time. Finally, the predictive similarity of the model was tested by constraining predictions to equality across time points. Then, the relations between our a priori predictors and the likelihood of profile membership were estimated using the same strategy.

Outcomes were incorporated into the final latent profile solution. We used the MODEL CONSTRAINT command of Mplus to systematically test mean-level differences across pairs of profiles (using the multivariate delta method: e.g., Raykov and Marcoulides 2004; for an application, see Kam et al. 2016). Following incorporation of these outcomes, we proceeded to tests of "explanatory similarity" by constraining the within-profile means of these outcomes to equality across time points. Sample inputs for all models are available in the online supplements.

\section{Results}

The fit indices of the time-specific LPA are reported in Table S6 of the online supplements. The AIC and ABIC kept on decreasing with the addition of profiles, the CAIC and BIC reached their lowest point at six profiles (or five for the CAIC at T3), the ALMR suggested three (T1 and T3) or four (T2) profiles, while the BLRT suggested seven (T2 and T3) or eight (T1) profiles. We thus relied on elbow plots, reported in Figures S1 to S3 of the online supplements. These figures show that the relative 
improvement in fit reached a relatively clear plateau around four profiles. The examination of the fourprofile solution and of adjacent three- and five- profile solutions confirmed the superiority of the fourprofile solution, thus supporting the configural similarity of this solution across time points. The fit indices from the final LPAs and for all longitudinal models are reported in Table 2.

A three-wave longitudinal LPA model of configural similarity including four-profiles at each time point was first estimated. Compared to this initial model, the next model resulted in a slightly higher value on the AIC and ABIC, but lower values on the BIC and CAIC, thereby supporting the structural similarity of this four-profile solution over time. However, the next model of dispersion similarity resulted in a higher value on all information criteria when compared to the model of structural similarity, thus failing to support the dispersion similarity of the profiles. Examination of the parameter estimates from these models revealed a reduced level of within-profile variability at the third time point, leading to the estimation of a model of partial dispersion similarity where levels of within-profile variability were constrained to be equal across the first two time points, but freely estimated at the third time point. Compared to the model of structural similarity, this model resulted in lower values on the CAIC, BIC, and ABIC thereby supporting the partial dispersion similarity of the solution. Finally, the model of distributional similarity resulted in an increase in the value of all information criteria when compared to the model of partial dispersion similarity, suggesting that the sizes of the profiles differ across time points. A detailed examination of the results did not suggest any meaningful model of partial distributional similarity. The model of partial dispersion similarity was thus retained for the next stages of the analyses, and converted to a complete LTA model. This final LTA model results in a relatively high level of classification accuracy, as illustrated by an entropy of .876, and is illustrated in Figure 1 (the exact within-profile means and variances of the indicators are reported in Table S7 of the online supplements). The relative size of the profiles at the different time points, and the transition probabilities across time points, are reported in Table 3.

Examination of these profiles argues against the added value of considering dimensions of union commitment. Indeed, all profiles mainly differ in their global level of union commitment, rather than showing clear qualitative differences based on specific dimensions. Profile 1 describes members presenting a high level of union commitment. This highly committed profile characterizes a declining proportion of members over time, decreasing from $21.82 \%$ of the sample at $\mathrm{T} 1$, to $19.47 \%$ at $\mathrm{T} 2$, and $13.34 \%$ at $\mathrm{T} 3$. This declines appears to be mainly related to a tendency for members corresponding to this profile to transit to Profile 2 (in which levels of union commitment are slightly lower) at the next time point (19.4\% make this transition between T1 and T2, and $62.2 \%$ between T2 and T3). Profile 2 describes members presenting moderately high levels of union commitment. Although this profile slightly increases in size over time (T1: $30.46 \%$; T2: $35.48 \%$; T3: $42.54 \%$ ), mainly due to members corresponding to Profile 1 transitioning to this profile at the next time point. Otherwise, membership into this profile appears to be fairly stable over time (with a stability of $89.4 \%$ between $\mathrm{T} 1$ and $\mathrm{T} 2$, and $82.7 \%$ between $\mathrm{T} 2$ and $\mathrm{T} 3$ ).

Profile 3 characterizes members presenting a moderately low level of union commitment. The relative size of this profile appears to be relatively stable across $\mathrm{T} 1$ (34.54\%) and $2(31.55 \%)$, and to slightly increase at T3 (36.74\%). Members corresponding to this profile at T1, when they transit to another profile at T2, tend to move to Profile $2(13.2 \%)$, thus contributing to part of the increase in the size of Profile 2. In contrast, membership into this profile appears to be more stable across T2 and T3 (81.7\% versus $75.1 \%$ across T1 and T2). Finally, Profile 4 describes members presenting low levels of union commitment. Like Profile 3, the size of this profile appears fairly stable across T1 (13.19\%) and T2 (13.50\%). However, the size of this profile shows a clear decrease at T3 (7.38\%). Although membership into this profile appears relatively stable across $\mathrm{T} 1$ and $\mathrm{T} 2(75.4 \%)$, it is not maintained across T2 and T3 (29.6\%). Members corresponding to this profile show a marked tendency to transit to Profile 3 ( $22.1 \%$ between $\mathrm{T} 1$ and $\mathrm{T} 2$, and $65.5 \%$ between $\mathrm{T} 2$ and $\mathrm{T} 3$ ). This marked transition probability explains the increase in the size of Profile 3 observed at T3.

\section{Demographics}

Demographic variables were added to the final LTA model of partial dispersion similarity. As shown in the Table 2, the null effects model resulted in the lowest values on all information criteria when compared to the alternative models, thus supporting the lack of relations between these demographic controls and the likelihood of membership into the various profiles. Examination of the detailed parameters estimates from these alternative models supported this conclusion regarding the lack 
of meaningful associations between the controls and the profiles, and the decision to exclude controls from further analyses.

\section{Predictors}

Predictors were then added to the final LTA model of partial dispersion similarity. As shown in Table 2, the model of predictive similarity resulted in lower values for the BIC and CAIC when compared to all alternative models. These results support the predictive similarity of the model. Results from the multinomial logistic regression estimated as part of this model are reported in Table 4. The findings showed that more positive union attitudes were associated with a higher likelihood of membership into the profiles ( 1 and 2 ) characterized by higher levels of union commitment than in the profiles ( 3 and 4) characterized by lower levels of union commitment. Union attitudes further predicted an increase in the likelihood of membership into the profile characterized by moderately low levels of union commitment (3) compared to the profile characterized by very low levels of union commitment (4), but did not differentially predict the likelihood of membership into the highly (1) versus moderately (2) committed profiles. The results similarly showed that having a more favorable view of union instrumentality predicted a higher likelihood of membership into the profile characterized by high (1), moderately high (2), and moderately low (3) levels of union commitment compared to the profile (4) characterized by very low level of union commitment, but did not differentially predict the likelihood of membership into the two profiles characterized by moderate levels of union commitment ( 2 and 3 ). However, union instrumentality also predicted a higher likelihood of membership into the profile characterized by a very high level of union commitment (1), compared to both profiles presenting moderate levels of union commitment (2 and 3). In contrast, the effects of union satisfaction were limited, with members' satisfaction about more formal aspects of their union's performance showing no significant associations with profile membership, and higher levels of satisfaction with union-member relationships predicting only a slightly increased likelihood of membership into the moderately committed profile (2) versus the profiles presenting moderately low (3) and low (4) levels of union commitment. It is noteworthy that, when significant, the effects of union satisfaction are much smaller (significant ORs: 2.101 and 2.938) than the effects of union attitudes and instrumentality (significant ORs: 0.152 to 58.083 ).

\section{Outcomes}

Outcomes were finally added to model. As shown in Table 2, compared with the model where the relations between profiles and outcomes were freely estimated across time points, the model of explanatory similarity resulted in lower values for the AIC, BIC, CAIC and ABIC, and was thus retained. The mean levels of outcomes in each profile are reported in Table 5. Because the profile-specific scores on each outcome are based on factor scores with a mean of 0 and a standard deviation of 1 , these results can be directly interpreted in standardized units - leading to between-profile differences that can be interpreted in effect size units. These results are consistent with the nature of the profiles, showing that levels of union participation (both UCB-I and UCB-O) are higher by about 1 standard deviation in the profile characterized by a high level of union commitment (1) than in the profile characterized by a low levels of union commitment (4), with the two moderate profiles ( 2 and 3 ) falling in between by about .5 standard deviation. For union participation at the level of the union itself as an organization (UCB-O) however, the two profiles characterized by lower levels of union commitment ( 3 and 4 ) are impossible to distinguish from one another.

\section{Discussion}

Union commitment has received considerable theoretical and empirical attention over the past four decades (Horsman et al. 2016). However, ever since the seminal work of Gordon et al. (1980), there has been a prominent debate regarding the dimensionality of the union commitment construct. Although research has led to the emergence of a popular three-dimensional measure (Kelloway et al., 1992), the correlations among the UCL, UCR and UCWW dimensions has generally been quite strong (e.g., Kelloway and Barling 1993; Shore et al. 1994; Mellor, Mathieu and Swim 1994; Sinclair and Tetrick 1995), thereby raising questions about whether the dimensions are truly distinct from a practical perspective. However, the variable-centered research strategy used to date assumes that the population is homogeneous and that observed relations among dimensions apply generally to all members of that population. In contrast, the person-centered approach (LPA/LTA) allows for the detection of subpopulations characterized by distinct configurations on these dimensions. If multiple subpopulations with qualitatively distinct profiles are detected, it suggests that the dimensions are indeed 
distinguishable, and subsequent analyses can be conducted to investigate the development and consequences of the unique combinations. If there are no detectable subpopulations, or if the subpopulations differ only quantitatively (i.e., in level rather than shape), it suggests that UCL, UCR and UCWW covary uniformly within the population and may reflect a unidimensional construct for practical purposes. Consequently, by allowing for both possibilities, the person-centered approach taken in this research affords a more stringent test of the dimensionality of UC than has been undertaken in the past. Additionally, by applying the person-centered analytic techniques of LPA and LTA to data obtained over a period of 10 years, we were able to advance previous research by investigating potential changes in UC and its relations to antecedents and outcomes.

\section{Dimensionality of Union Commitment}

Our analyses revealed four distinct profiles of UCL, UCR and UCWW across three time points over a 10-year period. The profile structure remained stable across all three occasions, with some variability in dispersion (within-profile variance) and distribution (profile size), particularly at the 10year follow-up. As illustrated in Figure 1, these profiles described highly committed, moderately committed, moderately uncommitted, and highly uncommitted union members. Although reflecting distinct subpopulations, these profiles differ only quantitatively, suggesting that UCL, UCR, and UCWW covary together when individual profiles are considered. In other words, despite the ability of variable-centered approaches to extract distinct, albeit highly correlated, dimensions of UC, when combinations of these dimensions are considered at an individual level, our person-centered results show that there is little value in considering these distinctions. This provides additional evidence that UC, as measured with the Kelloway et al.'s (1992) instrument, is best considered a unidimensional construct for practical purposes. Again, by providing the opportunity for the 'dimensions' to combine differently across subpopulations, these findings provide a quite stringent test of the dimensionality of UC. Pending replication in more diversified samples of unionized employees, one implication of these findings is that, without the need to separately measure distinct facets of UC, it might be possible to develop a shorter measure for use in research or practice without sacrificing content validity. Importantly, however, such a measure should include items from each of the facets to ensure adequate construct coverage.

\section{Changes in Union Commitment Over Time}

Over and above considerations regarding the dimensionality of the union commitment construct, the current results also have important substantive implications. Importantly, our results showed that the number (configural similarity) and nature (structural similarity) of members' UC profiles remained identical over their first 10 years of employment. This strongly suggests that these profiles reflect the operation of a consistent and meaningful set of mechanisms underlying the development of UC (see discussion of antecedents below). However, the results also revealed several interesting changes taking place over time. One of these is the reduction of the level of within-profile variability over time (lack of dispersion similarity), indicating that union members corresponding to each profile become more similar over time. The mechanisms responsible for this increasing similarity (e.g., socialization; common work experiences) are not addressed in the present investigation, but might warrant attention in future research.

It is important to note that the evidence for stability of profile structure, and increased withinprofile similarity, does not preclude the possibility of individuals transitioning across profiles. Indeed, our results showed that the relative size of the profiles changed over time (lack of distributional similarity). More specifically, our results showed that the number of highly committed members declined over time, with a substantial proportion transitioning to the moderately committed profile. Similarly, the number of members presenting very low levels of union commitment also decreased over time, again with a substantial proportion transitioning to the moderately low commitment profile. Importantly, these findings reveal that the changes over time reflect roughly equal changes in loyalty (UCL), responsibility (URR) and willingness to work on behalf of the union (UCWW), with no evidence that facets of the construct merge (e.g., loyal members becoming more willing to participate with increased experience) or diverge (e.g., loyal members making way for others to take more personal responsibility) over time. In contrast to the more extreme profiles, membership in the two moderate profiles demonstrated a much higher level of stability over time.

The greater movement toward rather than away from the moderate commitment profiles might be explained, in part, by regression to the mean (preliminary analyses revealed a very small negative 
association between initial levels of union commitment and their rate of change over time; Rogosa 1995). However, this explanation is mitigated to some extent by the fact that analyses were conducted using factor scores, thereby partially controlling for measurement error (Hsu, 1995). It is also noteworthy that the transitions continued, and indeed increased, over the 10-year span of the study. Indeed, our results showed that between $74.4 \%$ and $89.4 \%$ of members stayed in the same profiles over the initial 12-month period, whereas only 29.6 to $33.2 \%$ of members corresponding to the most extreme profiles (Profiles 1 and 4) stay in that same profile over a 10-year period. It is thus unlikely that this continued, and large, pattern of transitions away from the extreme profiles reflects only regression to the mean.

We can only speculate on other explanations for these transitions at this point. One possibility is that, because of their tendency to get more heavily involved in union activities, those with strong initial commitment levels experience some degree of exhaustion, or possibly disillusionment, over time (e.g., Morin, Vandenberghe, Turmel, Madore, and Maïano 2013). This possibility might be investigated in future research by adapting a measure of burnout (e.g., Maslach, Jackson and Leiter 1996) to the union context. In contrast, individuals with very low levels of initial union commitment could slowly come to realize some of the benefits of unionism as time goes by. This might come as the result of increased dissatisfaction with organizational policies and practices leading to a greater appreciation for the need for unions, and/or direct evidence of the benefits they have derived from union membership. Our findings regarding the antecedents of profile membership help to shed light on these possibilities.

\section{Antecedents and Outcomes of Union Commitment}

The antecedents examined in this study included both attitudes toward unions in general (global attitudes and instrumentality) and toward the respondents' own union (satisfaction with the formal and interpersonal aspects). The general attitude measures were more ideological in nature, and reflected beliefs about the contributions that unions make to society in general and their effectiveness as a force for positive change in the workplace, whereas the more specific measures addressed satisfaction with relations with the NALC and its effectiveness in improving conditions for letter carriers. Interestingly, our findings demonstrate that, across the three occasions of measurement, the general attitudes were better predictors of profile membership than were specific attitudes toward the NALC. The fact that satisfaction with the NALC did not predict the commitment profiles is somewhat surprising, and conflicts with some earlier findings (e.g., Snape et al. 2000). It may be that satisfaction with the NALC was less variable here than was the case in the earlier studies, and therefore not a major factor in shaping members' commitment. Although our findings do not rule out the possibility that satisfaction with the local union could contribute to general attitudes toward unions, and perhaps directly or indirectly to UC (Bamberger et al., 1999; Tan and Aryee, 2002) in other contexts, they do add evidence for the contribution made by the more general attitude toward unionism. It is important, therefore, to consider the latter findings in more detail.

It appears that members' ideological beliefs about unions in general can have a big impact on their profile of commitment to their own union. Our findings suggest that members who believe that unions are a positive force in society and have been instrumental in improving working conditions tend to be more committed, and that the stronger the beliefs, the stronger the commitment. In contrast, those who view unions as undemocratic and economically counterproductive tend to have the weakest commitment to their own union, independent of their satisfaction with the union itself. From a practical standpoint, this suggests the need for union leaders to emphasize more than just the contributions of the local union, but to also promote the contributions of unions, and unionism, in general. Although our findings suggest that positive union attitudes were predictive at all three time points, it might be particularly important to focus on the beliefs of newcomers. It appears from our data that membership in the high commitment profile is greatest in the first year but, for many of these individuals, commitment weakens over time. As noted previously, it is possible that these individuals become so actively engaged that they gradually experience some degree of burnout. However, it is also possible that they become complacent, particularly if they take the benefits of their own union's efforts for granted. They may need to be reminded of the broader contributions of unions and the need to continue to support unionism through continued commitment to the local union.

Those individuals who have very weak commitment to the union initially might also be affected by efforts to promote the benefits of unions more generally. It appears from our data that the strong antiunion sentiments that contribute to weak commitment in the first year among members of this very low 
profile weaken somewhat over time, with an accompanying increase in commitment. This might be due to experiences with the local union, although it does not seem to be a function of satisfaction with the union per se. It is possible that more of these uncommitted individuals would move to the moderate commitment profile with a more concerted effort on the part of union leaders to promote the benefits of unionism more generally. Our findings regarding the outcome of profile membership suggest that such efforts could have benefits for the union itself.

From an outcomes perspective, our results supported prior research in demonstrating that levels of union participation (both UCB-I and UCB-O) are greatest in the profiles characterized by a high level of union commitment (Profile 1) compared with the profile characterized by weak union commitment (Profile 4). However, differences were less detectable between the more moderate profiles, suggesting that more extreme levels of union commitment could be necessary to generate the required drive to more fully participate in personal actions which are supportive of both the union and fellow members.

\section{Strengths and Limitations}

The dataset used in the present study presents multiple important strengths, not the least of which is the reliance on a 10-year longitudinal follow-up of a single cohort of new union members. This unique opportunity to study the emergence of union commitment among new members over time removes the consideration of the potentially confounding effects of comparing short term changes in attitudes and behaviors between seasoned union members and union newcomers (Bayazit, Hammer, and Wazeter 2004). However, it is also important to keep several study limitations in mind when interpreting the results. First, the findings are based on a single US-based union operating in its own unique unionmanagement relationship. As such, future research would do well to assess the extent to which the present findings will generalize to samples of workers from a greater diversity of unions and cultural backgrounds. In addition, by focusing on members who remained with their organization and union over a 10-year period, our findings do not speak to the critical role that changes in employment and union membership might have on UC.

With regard to methodology, it is important to note that, despite relying on state-of-the-art missing data procedures, our ability to generalize our findings, particularly those related to profile transitions, is limited by the high rate of attrition observed in the present study. Our study is also limited by the current lack of analytic procedures to test associations between changes in profile membership and changes in outcomes levels over time (e.g., Ciarrochi et al. 2017). Finally, we were unable to control for the fact that participants were nested under local and state union constituency because information regarding nesting was not available to us. This might have led to some imprecision in the estimation of relations occurring between profile membership and the various predictors and outcomes considered at the individual level. As such, potentially important relations occurring at the local or state level might have been missed. For example, it remains possible that the increases in similarity observed within profiles over time might have been the result of initiatives taken at local or state levels, a possibility that could not be investigated in the present study. Clearly, future research would do well to integrate this higher analytical level (e.g., Mäkikangas, Tolvanen, Aunola, Feldt, Maunon, and Kinnunen 2018), and to consider a more diversified set of predictors and outcomes occurring at the local or state levels (e.g., union performance or participation rates).

These critical considerations for future research do not necessarily need to be based on new and costly data collections, but can instead be based on the analyses of data obtained in prior studies of union commitment. New and evolving methodologies provide the opportunity to look in novel ways at a wide array of incredibly rich data sets that might otherwise be neglected as researchers move on to new projects. This ability to capitalize on already available information and to examine it with new and evolving methods is the essence of substantive methodological synergies (e.g., Marsh and Hau 2007) and a possibly "greener" approach to research

\section{Conclusion}

In the context of increased variability in how researchers have operationalized the construct of union commitment, this study suggests that there may be limited value to the adoption of a multidimensional approach to the assessment of union commitment. In particular, the results reveal that the four (4) profiles of union commitment identified in this study primarily differ from one another on the global level of union commitment that characterizes them, rather than showing clear qualitative differences based on the specific dimensions of union commitment assessed in this study. Given the search for more parsimonious measures of constructs of interest, and limitations on the item count 
associated with survey designs, the findings of this study provide support for the reliance on simpler and shorter global measures of union commitment, the development of which will require increased scientific attention in the upcoming years. Another important practical implication of the present study derives from the evidence that union commitment profile membership was predicted better by ideological beliefs about unions than by satisfaction with the local union. Unions might be better served in building stronger commitment by emphasizing the benefits of unionism in general rather than focusing on local accomplishments.

\section{References}

Bamberger, Peter. A., Avraham N. Kluger, and Roenena Suchard. 1999. The antecedents and consequences of union commitment: A meta-analysis. Academy of Management Journal 42(3): 304-318.

Bayazit, Mahmut, Tove H. Hammer, and David L. Wazeter. 2004. Methodological challenges in union commitment studies. Journal of Applied Psychology 89(4): 738-747.

Catano, Victor M., Morgan Pond, and Kevin Kelloway. 2001. Exploring commitment and leadership in volunteer organizations. Leadership \& Organizational Development Journal 22(6): 256-263.

Chan, Andy, Ed Snape, and Tom Redman. 2011. Multiple foci and bases of commitment in a Chinese workforce. International Journal of Human Resource Management 22(16): 3290-3304.

Ciarrochi, Joseph, Alexandre J.S. Morin, Baljinder K. Sahdra, David Litalien, and Philip D. Parker. 2017. A longitudinal person-centered perspective on youth social support: Relations with psychological wellbeing. Developmental Psychology 53(6): 1154-1169.

Collins, Linda, and Stephanie Lanza. 2010. Latent class and latent transition analysis: With applications in the social, behavioral, and health sciences. New York, NY: Wiley.

Despande, Satish P., and Jack Fiorito. 1989. Specific and general beliefs in union voting models. Academy of Management Journal 32(4): 883-897.

Fields, Mitchell W., and James Thacker. 1992. Influence of quality of work life on company and union commitment. Academcy of Management Journal 35(2): 439-450.

Fiorito, Jack, Daniel G. Gallagher, and Cynthia Fukami. 1988. Satisfaction with union representation. Industrial and Labor Relations Review 41(2): 294-307.

Friedman, Lee, and Robert Harvey. 1986. Factors of union commitment: The case for a lower dimensionality. Journal of Applied Psychology 71(3): 371-376.

Fullagar, Clive. 1986. A factor analytic study on the validity of a union commitment scale. Journal of Applied Psychology 71(1): 129-136.

Fullagar, Clive, and Julian Barling. 1989. A longitudinal test of a model of the antecedents and consequences of union loyalty. Journal of Applied Psychology 74(2): 213-227.

Fullagar, Clive, and Julian Barling. 1991. Predictors and outcomes of different patterns of organizational and union loyalty. Journal of Occupational Psycholog, 64(2): 129-143.

Fullagar, Clive, Paul F. Clark, Daniel G. Gallagher, and Micheal Gordon. 1994. A model of the antecedents of early union commitment: the role socialization experiences and steward characteristics. Journal of Organizational Behavior 15(6): 517-533.

Fullagar, Clive, Daniel G. Gallagher, Paul F. Clark, and Anthony Carroll. 2004. Union commitment and participation: A 10-year longitudinal study. Journal of Applied Psychology 89(4): 730-737.

Fullagar, Clive, Daniel G. Gallagher, Michael Gordon, and Paul F. Clark. 1995. Impact of early socialization on union commitment and participation: A longitudinal study. Journal of Applied Psychology 80(1): 147-157.

Fullagar, Clive, Don McCoy, and Carla Schull. 1992. The socialization of union loyalty. Journal of Organizational Behavior 13(1): 13-27.

Getman, Julius G., Stephen Goldberg, and Jeanne Herman. 1976. Union Representation Elections: Law and Reality. New York, NY: Russell Sage.

Gillet, Nicolas, Alexandre J.S. Morin, Baptiste Cougot, and Marylène Gagné. 2017. Workaholism Profiles: Associations with Determinants, Correlates, and Outcomes. Journal of Occupational and Organizational Psychology 90(4): 559-586.

Gillet, Nicolas, Alexandre J.S. Morin, Tiphaine Huyghebaert, Lucie Burger, Axel Maillot, Aurélie Poulin, and Elodie Tricard. 2018. University students' need satisfaction trajectories: A growth mixture analysis. Learning \& Instruction. Early View doi: 10.1016/j.learninstruc.2017.11.003

Gordon, Michael E., John W. Philpot, Robert E. Burt, Cynthia Thompson, and William Spiller. 1980. 
Commitment to the union: Development of a measure and an examination of its correlates. Journal of Applied Psychology 65(4): 479-499.

Hammer, Tove H., Mahmut Bayazit, and David Wazeter. 2009. Union leadership and member attitudes: A multi-level analysis. Journal of Applied Psychology 94(2): 392-410.

Hipp, John R., and Daniel J. Bauer. 2006. Local solutions in the estimation of growth mixture models. Psychological Methods 11(1): 36-53.

Hoell, Robert 2004. How employee involvement affects union commitment. Journal of Labor Research 25(2): 268-277.

Horsman, Patrick., Daniel G. Gallagher, and Kevin Kelloway. 2016. The rise, resurrection, and growth of union commitment research. In John P. Meyer (Ed.), The Handbook of Employee Commitment, pp. 165-177. Edward Elgar Publishing.

Hsu, Louis. 1995. Regression toward the mean associated with measurement error and the identification of improvement and deterioration in psychotherapy. Journal of Consulting \& Clinical Psychology 63(1), 141-144.

Iverson, Roderick, and Sarosh Kuruvilla. 1995. Antecedents of union loyalty: The influence of individual dispositions and organizational context. Journal of Organizational Behavior 16(6): $557-$ 582.

Kam, Chester, Alexandre J. S. Morin, John P. Meyer, and Laryssa Topolnytsky. 2016. Are commitment profiles stable and predictable? Journal of Management 42(6): 1462-1490.

Kelloway, Kevin and Julian Barling. 1993. Members' participation in local union activities: Measurement, prediction and replication. Journal of Applied Psychology 78(2): 262-279.

Kelloway, Kevin., Victor M. Catano, and Robert Southwell. 1992. The construct validity of union commitment: Development and dimensionality of a shorter scale. Journal of Occupational and Organizational Psychology 65(3): 197-211.

Klandermans, Bert. 1989. Union commitment: Replications and tests in the Dutch context. Journal of Applied Psychology 74(6): 869-875.

Kuruvila, Sarosh, and Roderick Iverson. 1993. A confirmatory factor analysis of union commitment in Australia. Journal of Industrial Relations 35(3): 436-452.

Ladd, Robert T., Michael E. Gordon, Laura. Beauvais, and Richard Morgan. 1982. Union commitment: Replication and extension. Journal of Applied Psychology 67(5): 640-644.

Lo, Yungtai, Nancy Mendell, and Donald Rubin. 2001. Testing the number of components in a normal mixture. Biometrika 88(5): 767-778.

Mäkikangas, Anne, Asko Tolvanen, Kaisa Aunola, Taru Feldt, Saija Maunon, and Ulla Kinnunen (2018). Multilevel latent profile analysis with covariates. Organizational Research Methods. Early view doi: $10.1177 / 1094428118760690$

Magenau, John, James Martin, and Melanie Peterson. 1988. Dual and unilateral commitment among stewards and rank-and-file members. Academy of Management Journal 31(2): 359-276.

Marsh, Herbert W., and Kit-Tai Hau. 2007. Applications of latent-variable models in educational psychology: The need for methodological-substantive synergies. Contemporary Educational Psychology 32(1): 151-171.

Marsh, Herbert W., Olivier Lüdtke, Ulrich Trautwein, and Alexandre J.S. Morin. 2009. Classical latent profile analysis of academic self-concept dimensions: Synergy of person- and variable-centered approaches to theoretical models of self-concept. Structural Equation Modeling 16(2):191-225.

Maslach, Christina, Susan Jackson, and Michael P. Leiter. (1996). MBI Manual, $3^{\text {rd }}$ Edition. Palo Alto, CA: Consulting Psychologists Press.

McDonald, Roderick. 1970. Theoretical foundations of principal factor analysis and alpha factor analysis. British Journal of Mathematical and Statistical Psychology 23(1): 1-21.

McShane, Steven 1986. General union attitude: A construct validation. Journal of Labor Research 7(4): 403-417.

Meyer, John P., and Nathalie J. Allen. 1997. Commitment in the Workplace: Theory, Research and Application. Thousand Oaks, CA: Sage.

Meyer, John P., and Alexandre J.S. Morin. 2016. A person-centered approach to commitment research: Theory, research, and methodology. Journal of Organizational Behavior 37(4): 584-612.

Mellor, Steven. 1992. The influence of layoff severity on post-layoff union commitment among survivors: The moderating effect of the perceived legitimacy of the layoff account. Personnel 
Psychology 45(3): 549-600.

Mellor, Steven, John Mathieu, and Janet Swim. 1994. Cross level analysis of the influence of local union structure on women's and men's union commitment. Journal of Applied Psychology 79(2): 203210.

Millsap, Roger. 2011. Statistical approaches to measurement invariance. New York: Taylor \& Francis.

Monnot, Matthew, Stephen Wagner, and Terry Beehr. 2011. A contingency model of union commitment and participation: Meta-analysis of the antecedents of militant and nonmilitant activities. Journal of Organizational Behavior 32(8): 1127-1146.

Morin, Alexandre J.S. 2016. Person-centered research strategies in commitment research. In John P. Meyer (Ed.), The Handbook of Employee Commitment, pp. 490-508. Cheltenham, UK: Elgar.

Morin, Alexandre J.S., Jean-Sébastien Boudrias, Herbert W. Marsh, Isabelle Madore, and Pascale Desrumaux. 2016. Further reflections on disentangling shape and level effects in person-centered analyses. Structural Equation Modeling 23(3): 438-454.

Morin, Alexandre J.S., Jean-Sébastien Boudrias, Herbert W. Marsh, Dennis M. McInerney, Véronique Dagenais-Desmarais, Isabelle Madore, and David Litalien. 2017. Complementary variable-and person-centered approaches to the dimensionality of psychometric constructs. Journal of Business \& Psychology 32(4): 395-419.

Morin, Alexandre J.S., and David Litalien. 2017. Webnote: Longitudinal tests of profile similarity and latent transition analyses. Montreal, QC: Substantive Methodological Synergy Research Laboratory. http://smslabstats.weebly.com/uploads/1/0/0/6/100647486/lta_distributional_similarity_v02.pdf

Morin, Alexandre J.S., Christophe Maïano, Benjamin Nagengast, Herbert W. Marsh, Julien Morizot, and Michel Janosz. 2011. Growth mixture modeling of adolescents trajectories of anxiety: The impact of untested invariance assumptions on substantive interpretations. Structural Equation Modeling 18(4): 613-648.

Morin, Alexandre J.S., John P. Meyer, Jordane Creusier, and Franck Biétry. 2016. Multiple-group analysis of similarity in latent profile solutions. Organizational Research Methods 19(2): 231-254.

Morin, Alexandre, Christian Vandenberghe, Marie-Josée Turmel, Isabelle Madore, \& Christophe Maïano (2013). Probing into Commitment's Nonlinear Relationships to Work Outcomes. Journal of Managerial Psychology 28(2): 202-223.

Morin, Alexandre J.S., and John J.C.K. Wang. 2016. A gentle introduction to mixture modeling using physical fitness data. In Nikos Ntoumanis, \& Nicholas D. Myers (Eds.), An introduction to intermediate and advanced statistical analyses for sport \& exercise scientists, pp. 183-210. London, UK: Wiley.

Morishima, Motohiro. 1995. Union loyalty among white-collar workers in Japan. Journal of Organizational Behavior 16(6): 609-635.

Muthén, Bengt. 2002. Beyond SEM: General latent modeling. Behaviormetrika 29(1): 81-117.

Muthén, Bengt. 2003. Statistical and substantive checking in growth mixture modeling: Comment on Bauer and Curran. 2003. Psychological Methods 8(3): 369-377.

Muthén, Linda, and Bengt Muthén. 2014. Mplus user's guide. Los Angeles: Muthén \& Muthén.

Peugh, James, and Xitao Fan. 2013. Modeling unobserved heterogeneity using latent profile analysis: A Monte Carlo simulation. Structural Equation Modeling 20(4): 616-639.

Porter, Lyman, William Crampon, and Frank Smith. 1976. Organizational commitment and managerial turnover: A longitudinal study. Organizational Behavior and Human Performance 15(1): 87-98.

Purcell, Theodore. V. 1953. The worker speaks his mind on company and union. Cambridge: Harvard.

Quinn, Robert, and Graham Staines. 1978. The 1977 quality of employment survey. Ann Arbor, MI: Institute for Social Research, University of Michigan.

Raykov, Tenko, and George Marcoulides. 2004. Using the delta method for approximate interval estimation of parameter functions in SEM. Structural Equation Modeling 11(4): 621-637.

Redman, Tom, and Ed Snape. 2005. Exchange ideology and member-union relationships: An evaluation of moderation effects. Journal of Applied Psychology 90(4): 765-773.

Rogosa, David (1995). Myths and methods: "Myths about longitudinal research" plus supplemental questions. In John M. Gottman, (Ed.), The analysis of change, pp. 3-65. New Jersey: Erlbaum.

Shore, Lynn, Lois Tetrick, Robert Sinclair, and Lucy Newton. 1994. Validation of a measure of perceived union support. Journal of Applied Psychology 79(6): 971-977.

Sinclair, Robert, and Lois Tetrick. 1995. Social exchange and union commitment: Comparison of union 
instrumentality and union support perceptions. Journal of Organizational Behavior 16(S1): 669680.

Skarlicki, Daniel, and Gary Latham. 1996. Increasing citizenship behavior within a labor union: A test of organizational justice theory. Journal of Applied Psychology 81(2): 161-169.

Skrondal, Anders, and Petter Laake. 2001. Regression among factor scores. Psychometrika 66(4): 563576.

Snape, Ed, Tom Redman, and Andy Chan. 2000. Commitment to the union: A survey of research and the implications for industrial relations and trade unions. International Journal of Management Reviews 2(3): 205-230.

Snape, Ed, tom Redman, and Julian Gould-Williams. 2014. How "collective" is union citizenship behavior? Industrial and Labor Relations Review 67(4): 1306-1325.

Stagner, Ross. 1954. Dual allegiance as a problem in modern society. Personnel Psychology 7(1): 41-47.

Sverke, Magnus, and Anders Sjoberg. 1994. Dual commitment to company and union in Sweden: An examination of predictors and taxonomic split methods. Economic and Industrial Democracy 15(4): 531-564.

Tan, Hwee, and Samuel Aryee. 2002. Antecedents and outcomes of union loyalty: A constructive replication and an extension. Journal of Applied Psychology 87(4): 715-722.

Tein, Jenn-Yun, Stefany Coxe, and Heining Cham. 2013. Statistical power to detect the correct number of classes in latent profile analysis. Structural Equation Modeling 20(4): 640-657.

Tetrick, Lois, James Thacker, and Mitchell Fields. 1989. Evidence of the stability of the four dimensions of the commitment to union scale. Journal of Applied Psychology 74(5): 819-822.

Thacker, James, Mitchell Fields, and Lois Tetrick. 1989. The factor structure of union commitment: An application of confirmatory factor analysis. Journal of Applied Psychology 74(2): 228-232.

Tofighi, Davood, and Craig Enders. 2008. Identifying the correct number of classes in growth mixture models. In Gregory R. Hancock \& Karen M. Samuelsen (Eds.), Advances in latent variable mixture models, pp. 317-341. Charlotte, NC: Information Age.

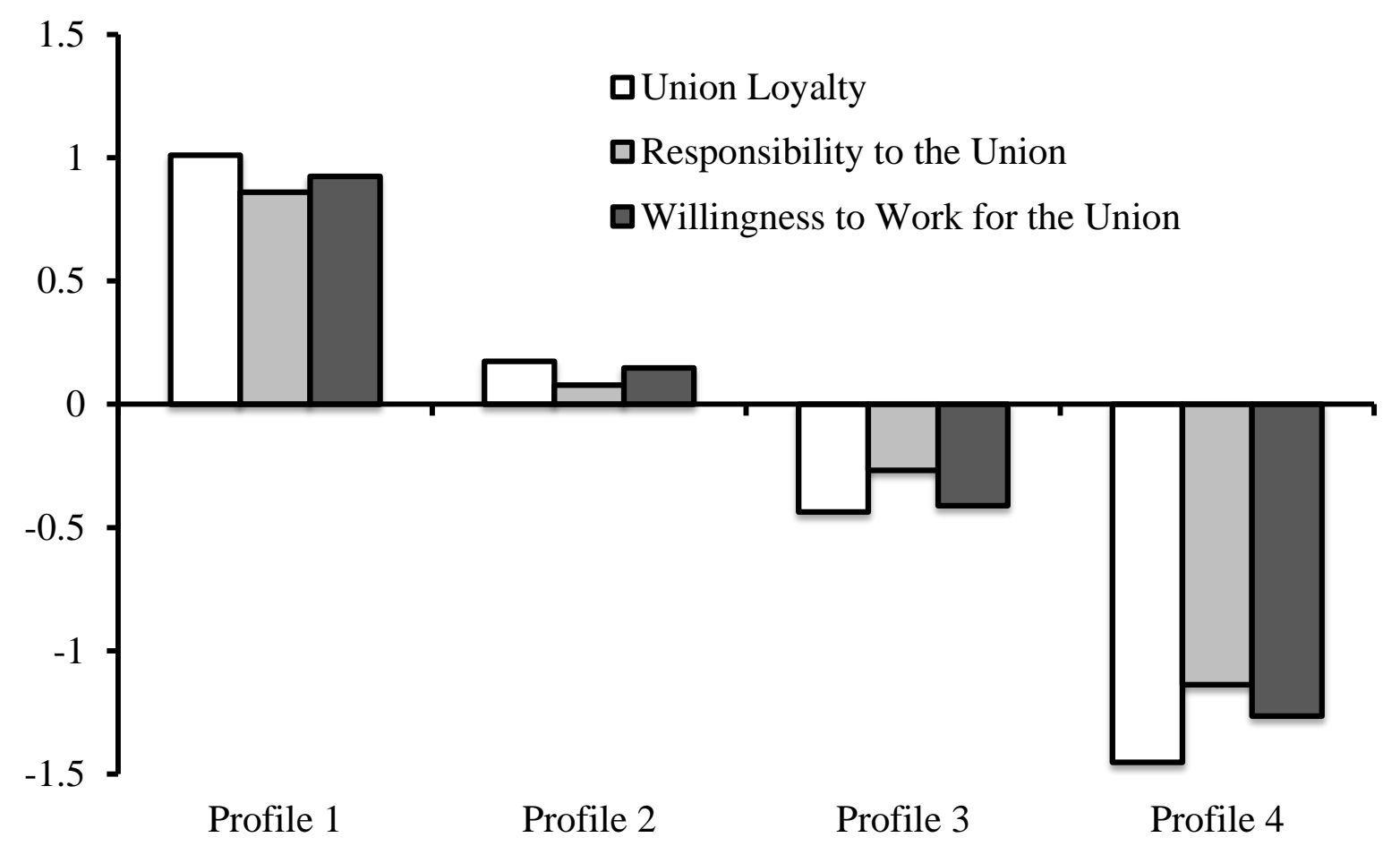

Figure 1. Latent Profiles Based on the Longitudinal Model of Partial Dispersion Similarity.

Note. Profile indicators are estimated from factor scores with mean of 0 and a standard deviation of 1. 
Table 1

Correlations Between all Variables (Factor Scores)

\begin{tabular}{|c|c|c|c|c|c|c|c|c|c|c|c|c|c|}
\hline & UCL1 & $\begin{array}{l}\text { UCR1 } \\
\end{array}$ & UCWW & UCL2 & UCR2 & UCWW2 & UCL3 & UCR3 & UCWW3 & UA1 & UI1 & USF1 & USR1 \\
\hline$\overline{\text { UCL1 }}$ & .925 & & & & & & & & & & & & \\
\hline UCR1 & $.734 * *$ & .830 & & & & & & & & & & & \\
\hline UCWW1 & $.849 * *$ & $.691 * *$ & .776 & & & & & & & & & & \\
\hline UCL2 & $.770 * *$ & $.607 * *$ & $.611 * *$ & .925 & & & & & & & & & \\
\hline UCR2 & $.522 * *$ & $.739 * *$ & $.482 * *$ & $.736 * *$ & .830 & & & & & & & & \\
\hline UCWW2 & $.613 * *$ & $.526 * *$ & $.744 * *$ & $.826^{* * *}$ & $.668 * *$ & .776 & & & & & & & \\
\hline UCL3 & $.510 * *$ & $.427 * *$ & $.365 * *$ & $.609 * *$ & $.362 * *$ & $.528 * *$ & .925 & & & & & & \\
\hline UCR3 & $.262 * *$ & $.432 * *$ & $.203 * *$ & $.332 * *$ & $.389 * *$ & $.274 * *$ & $.750 * *$ & .830 & & & & & \\
\hline UCWW3 & $.376 * *$ & $.376 * *$ & $.573 * *$ & $.336^{* *}$ & $.232 * *$ & $.619 * *$ & $.776 * *$ & $.630 * *$ & .776 & & & & \\
\hline UI1 & $.737 * *$ & $.527 * *$ & $.543 * *$ & $.659 * *$ & $.426 * *$ & $.476^{* *}$ & $.439 * *$ & $.208 * *$ & $.229 * *$ & $.810 * *$ & .710 & & \\
\hline USF1 & $.597 * *$ & $.389 * *$ & $.419 * *$ & $.550 * *$ & $.320 * *$ & $.379 * *$ & $.325 * *$ & $.109 * *$ & $.129 * *$ & $.636 * *$ & $.832 * *$ & .839 & \\
\hline USR1 & $.589 * *$ & $.386 * *$ & $.402 * *$ & $.519 * *$ & $.308 * *$ & $.341 * *$ & $.302 * *$ & $.109 * *$ & $.104^{* *} *$ & $.632 * *$ & $.821 * *$ & $.935 * *$ & .894 \\
\hline UA2 & $.536 * *$ & $.428 * *$ & $.422 * *$ & $.709 * *$ & $.536 * *$ & $.591 * *$ & $.446 * *$ & $.263 * *$ & $.252 * *$ & $.710 * *$ & $.682 * *$ & $.457 * *$ & $.441 * *$ \\
\hline UI2 & $.654 * *$ & $.489 * *$ & $.495 * *$ & $.797 * *$ & $.548 * *$ & $.637 * *$ & $.551 * *$ & $.319 * *$ & $.310 * *$ & $.749 * *$ & $.827 * *$ & $.671 * *$ & $.615^{* *}$ \\
\hline USF2 & $.504 * *$ & $.352 * *$ & $.369 * *$ & $.674 * *$ & $.437 * *$ & $.533 * *$ & $.424 * *$ & $.213 * *$ & $.206 * *$ & $.499 * *$ & $.616^{* *}$ & $.716^{* *}$ & $.647 * *$ \\
\hline USR2 & $.527 * *$ & $.381 * *$ & $.369 * *$ & $.691 * *$ & $.463 * *$ & $.526 * *$ & $.398 * *$ & $.210 * *$ & $.160 * *$ & $.553 * *$ & $.646 * *$ & $.715 * *$ & $.710 * *$ \\
\hline UA3 & $.433 * *$ & $.336 * *$ & $.345 * *$ & $.570 * *$ & $.364 * *$ & $.505 * *$ & $.687 * *$ & $.462 * *$ & $.518 * *$ & $.595 * *$ & $.547 * *$ & $.275^{* *} *$ & $.243 * *$ \\
\hline UI3 & $.488 * *$ & $.341 * *$ & $.332 * *$ & $.615^{* * *}$ & $.361 * *$ & $.492 * *$ & $.762 * *$ & $.474 * *$ & $.517 * *$ & $.421 * *$ & $.651 * *$ & $.546^{* *}$ & $.478 * *$ \\
\hline USR3 & $413 * *$ & $293 * *$ & $268 * *$ & $.542 * *$ & $.316^{* * *}$ & $.423 * *$ & $685^{* * *}$ & $.407 * *$ & $.449 * *$ & $.397 * *$ & $.543 * *$ & $.506^{* *}$ & $.511 * *$ \\
\hline UCBI2 & $.143 * *$ & $.135 * *$ & $.208 * *$ & $.232 * *$ & $.309 * *$ & $.271 * *$ & .032 & .047 & .062 & .095 & .074 & -.016 & -.018 \\
\hline $\mathrm{UCBO} 2$ & $.140 * *$ & $.150 * *$ & $.203 * *$ & $.232 * *$ & $.282 * *$ & $.277 * *$ & $.109 *$ & $.114^{*}$ & $.135 * *$ & .074 & .055 & -.031 & $.140 * *$ \\
\hline UCBI3 & .064 & $.123^{*}$ & $.127 *$ & $.103^{*}$ & $.134 * *$ & $.192 * *$ & $.283 * *$ & $.322 * *$ & $.337 * *$ & .036 & .037 & -.025 & .064 \\
\hline $\mathrm{UCBO} 3$ & $.100 *$ & $.141 * *$ & $.145 * *$ & $.136^{* * *}$ & $.179 * *$ & $211 * *$ & $.272 * *$ & $.280 * *$ & $.309 * *$ & .027 & .013 & -.058 & $.100^{*}$ \\
\hline Sex & .014 & $-.084 *$ & -.070 & -.002 & -.068 & -.073 & .007 & -.042 & -.078 & $.133 * *$ & $.103 *$ & .043 & .073 \\
\hline Age & -.054 & .019 & -.016 & -.040 & .012 & .002 & .012 & .046 & .053 & .016 & -.023 & -.046 & -.048 \\
\hline Education & -.071 & -.047 & -.050 & -.061 & -.014 & -.058 & -.069 & -.032 & -.055 & $-.105 * *$ & $-.085 *$ & -.045 & -.041 \\
\hline Tenure & .032 & .056 & .019 & .059 & .069 & .047 & .053 & .051 & .029 & .016 & .037 & -.023 & -.044 \\
\hline
\end{tabular}

Note. $* p<.05 ; * *<.01 ; \mathrm{UCL}=$ union commitment: union loyalty; UCR $=$ union commitment: responsibility to the union; UCWW $=$ union commitment: willingness to work for the union; UA = union attitudes; UI = union instrumentality; USF = union satisfaction: formal; USR = union satisfaction:

relationships; $\mathrm{UCBI}=$ union citizenship behaviors: interpersonal helping; $\mathrm{UCBO}=$ union citizenship behaviors: union as an organization; $1=$ time $1 ; 2=$ time 2; $3=$ time 3; composite reliability scores reported in the diagonal (italicized); profile indicators, predictors and outcomes are estimated from factor scores with mean of 0 and a standard deviation of 1 . 
Table 1 (Continued)

\begin{tabular}{|c|c|c|c|c|c|c|c|c|c|c|c|c|c|c|c|}
\hline & UA2 & UI2 & USF2 & USR2 & UA3 & UI3 & USF3 & USR3 & $\mathrm{UCBI} 2$ & $\mathrm{UCBO} 2$ & $\mathrm{UCBI} 3$ & $\mathrm{UCBO} 3$ & Sex & Age & Education \\
\hline UA2 & .776 & & & & & & & & & & & & & & \\
\hline UI2 & $.838 * *$ & .710 & & & & & & & & & & & & & \\
\hline USF2 & $.621 * *$ & $.827 * *$ & .832 & & & & & & & & & & & & \\
\hline USR2 & $.646 * *$ & $.826 * *$ & $.928 * *$ & .889 & & & & & & & & & & & \\
\hline UA3 & $.708 * *$ & $.760 * *$ & $.466 * *$ & $.417 * *$ & .776 & & & & & & & & & & \\
\hline UI3 & $.594 * *$ & $.752 * *$ & $.615^{* *}$ & $.542 * *$ & $.810 * *$ & .710 & & & & & & & & & \\
\hline USF3 & $.542 * *$ & $.635^{* *}$ & $.564 * *$ & $.494 * *$ & $.665^{* *}$ & $.832 * *$ & .814 & & & & & & & & \\
\hline USR3 & $.509 * *$ & $.662 * *$ & $.619 * *$ & $.597 * *$ & $.647 * *$ & $.830 * *$ & $.914^{* *}$ & .891 & & & & & & & \\
\hline UCBI2 & $.202 * *$ & $.192 * *$ & $.111 *$ & $.127 *$ & $.110^{*}$ & .027 & -.025 & .017 & .884 & & & & & & \\
\hline $\mathrm{UCBO} 2$ & $.207 * *$ & $.194 * *$ & $.121 *$ & $.128 *$ & $.142 * *$ & .064 & .006 & .040 & $.852 * *$ & .890 & & & & & \\
\hline UCBI3 & $.107 *$ & $.121 *$ & .055 & .050 & $.199 * *$ & $.151 * *$ & $.107 *$ & $.132 * *$ & .055 & $.237 * *$ & .884 & & & & \\
\hline $\mathrm{UCBO} 3$ & $.135 * *$ & $.117^{*}$ & .053 & .049 & $.203 * *$ & $.134 * *$ & .078 & $.106^{*}$ & $.215^{* *}$ & $.452 * *$ & $.804 * *$ & .890 & & & \\
\hline Sex & $.089 *$ & .058 & .021 & .049 & .053 & .012 & .073 & .070 & -.031 & -.070 & .052 & .016 & & & \\
\hline Age & .045 & .010 & -.025 & -.032 & .063 & .038 & .058 & .049 & -.089 & -.060 & -.085 & -.035 & $-.244^{*}$ & & \\
\hline Education & $-.094 *$ & $-.088 *$ & -.030 & -.045 & $-.107 *$ & -.071 & $-.079 *$ & -.060 & -.018 & -.026 & -.065 & $-.139 *$ & $-.104 *$ & .064 & \\
\hline Tenure & .071 & .053 & .018 & -.007 & .063 & .050 & .036 & .025 & .083 & $.127 *$ & .022 & .048 & $-.083 *$ & $.201 *$ & .000 \\
\hline
\end{tabular}

Note. ${ }^{*} p<.05 ; * *<.01 ; \mathrm{UCL}=$ union commitment: union loyalty; UCR = union commitment: responsibility to the union; UCWW = union commitment: willingness to work for the union; UA = union attitudes; UI = union instrumentality; USF = union satisfaction: formal; USR = union satisfaction:

relationships; $\mathrm{UCBI}=$ union citizenship behaviors: interpersonal helping; $\mathrm{UCBO}=$ union citizenship behaviors: union as an organization; $1=$ time $1 ; 2=$ time $2 ; 3=$ time 3; composite reliability scores reported in the diagonal (italicized); profile indicators, predictors and outcomes are estimated from factor scores with mean of 0 and a standard deviation of 1 . 
Table 2

Results from the Latent Transition Analyses Estimated on the Full Sample

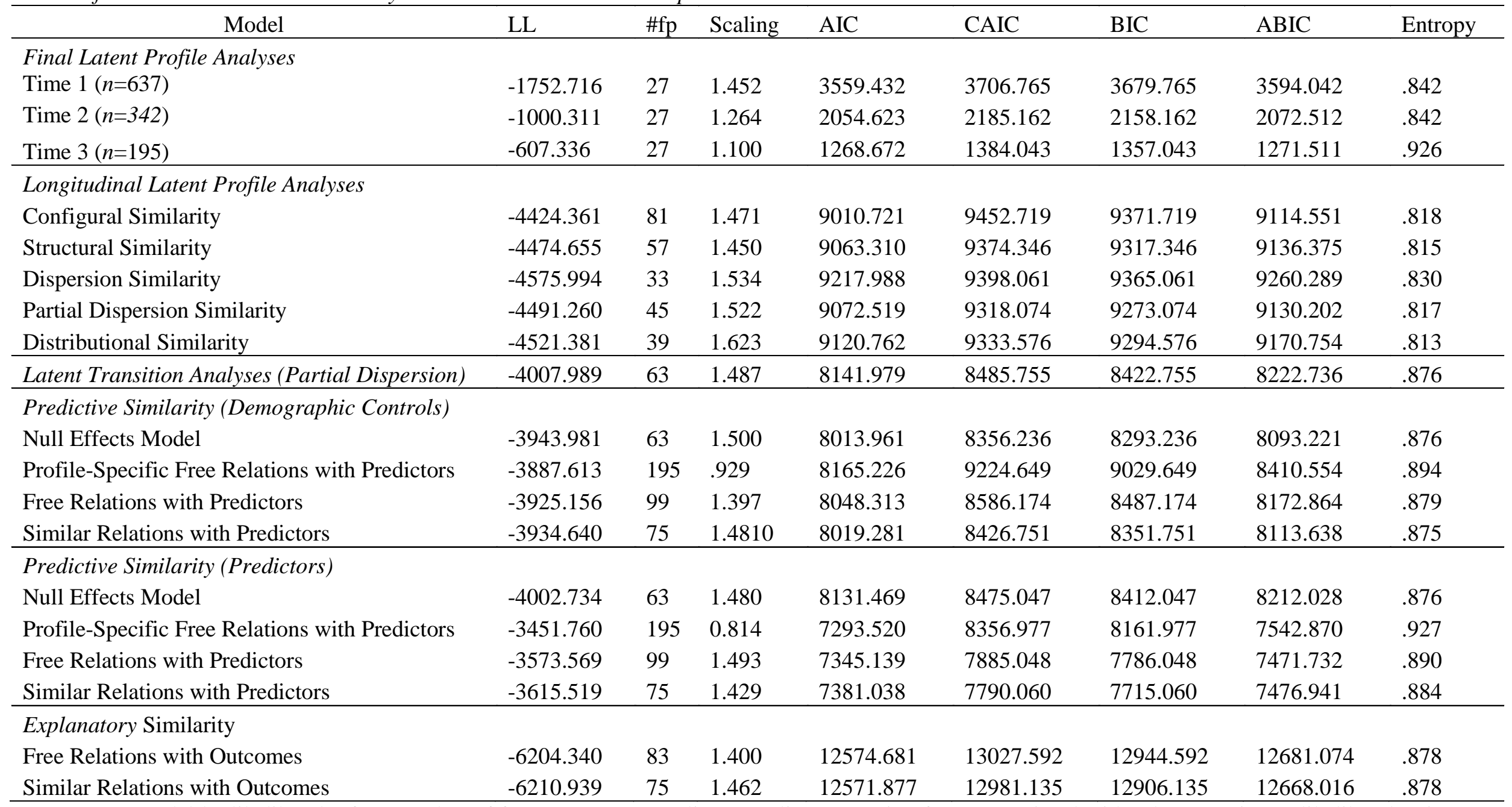

Note. $\mathrm{LL}=$ model loglikelihood; \#fp = number of free parameters; scaling = scaling correction factor associated with robust maximum likelihood estimates; $\mathrm{AIC}=$ Akaïke information criteria; $\mathrm{CAIC}=$ constant AIC; $\mathrm{BIC}=$ Bayesian information criteria; $\mathrm{ABIC}=$ sample size adjusted BIC . 
Table 3

Relative Size of the Profiles and Transitions Probabilities for the Latent Transition Analyses

\begin{tabular}{lccccc}
\hline & & \multicolumn{4}{c}{ Transition Probabilities to Time 2 Profiles } \\
\cline { 3 - 6 } & Relative Size & Profile 1 & Profile 2 & Profile 3 & Profile 4 \\
\hline Time 1 Profiles & & & & & \\
Profile 1 & $21.82 \%$ & .744 & .194 & .015 & .046 \\
Profile 2 & $30.46 \%$ & .030 & .894 & .076 & .000 \\
Profile 3 & $34.54 \%$ & .051 & .132 & .751 & .065 \\
Profile 4 & $13.19 \%$ & .025 & .000 & .221 & .754 \\
Relative Size & & $19.47 \%$ & $35.48 \%$ & $31.55 \%$ & $13.50 \%$ \\
\cline { 3 - 6 } & & \multicolumn{4}{c}{ Transition Probabilities to Time 3 Profiles } \\
Time 2 Profiles & Relative Size & Profile 1 & Profile 2 & Profile 3 & Profile 4 \\
Profile 1 & & \multicolumn{4}{c}{} \\
Profile 2 & $19.47 \%$ & .332 & .622 & .016 & .030 \\
Profile 3 & $35.48 \%$ & .111 & .827 & .031 & .031 \\
Profile 4 & $31.55 \%$ & .086 & .025 & .817 & .072 \\
Relative Size & $13.50 \%$ & .049 & .000 & .655 & .296 \\
\hline & & $13.34 \%$ & $42.54 \%$ & $36.74 \%$ & $7.38 \%$ \\
\hline
\end{tabular}




\section{Table 4}

Results from Multinomial Logic Regressions for the Time-Invariant Effects of the Predictors on Profile Membership.

\begin{tabular}{|c|c|c|c|c|c|c|}
\hline & \multicolumn{2}{|c|}{ Latent profile 1 vs. 4} & \multicolumn{2}{|c|}{ Latent profile 2 vs. 4} & \multicolumn{2}{|c|}{ Latent profile 3 vs. 4} \\
\hline Union Instrumentality & $4.062(0.723)^{* *}$ & 58.083 & $2.187(0.545)^{* *}$ & 8.910 & $1.589(0.475)^{* *}$ & 4.900 \\
\hline Union Satisfaction: Formal Aspects & $0.013(0.650)$ & 1.014 & $-0.386(0.525)$ & 0.680 & $-0.148(0.474)$ & 0.862 \\
\hline \multirow{2}{*}{ Union Satisfaction: Union-Member Relationships } & \multicolumn{2}{|c|}{ Latent profile 1 vs. 3} & \multicolumn{2}{|c|}{ Latent profile 2 vs. 3} & \multicolumn{2}{|c|}{ Latent profile 2 vs. 1} \\
\hline & Coef. (SE) & OR & Coef. (SE) & OR & Coef. (SE) & OR \\
\hline Union Attitudes & $0.980(0.374)^{* *}$ & 2.663 & $0.670(0.274)^{*}$ & 1.954 & $-0.304(.270)$ & 0.738 \\
\hline Union Satisfaction: Union-Member Relationships & $-0.016(0.515)$ & 0.984 & $0.742(0.356)^{*}$ & 2.101 & $0.746(.437)$ & 2.109 \\
\hline
\end{tabular}

Notes. $* p<.05 ; * * p<.01$; the predictors are estimated from factor scores with mean of 0 and a standard deviation of $1 ; \mathrm{SE}=$ standard error of the coefficient; OR = odds ratio. The coefficients and OR reflects the effects of the predictors on the likelihood of membership into the first listed profile relative to the second listed profile.

\section{Table 5}

Time-Invariant Associations between Profile Membership and the Outcomes

\begin{tabular}{|c|c|c|c|c|c|c|c|c|c|c|c|c|}
\hline & \multicolumn{4}{|c|}{ Profile-Specific Means } & \multicolumn{7}{|c|}{ Mean Differences } & \multirow{2}{*}{$\begin{array}{l}\text { Significant } \\
\text { Differences }\end{array}$} \\
\hline & Profile 1 & Profile 2 & Profile 3 & Profile 4 & $1 \mathrm{Vs} 2$ & $1 \mathrm{Vs} 3$ & $1 \mathrm{Vs} 4$ & $2 \mathrm{Vs} 3$ & $2 \mathrm{Vs} 4$ & $3 \mathrm{Vs} 4$ & Mean & \\
\hline $\begin{array}{l}\text { Union Citizenship Behaviors: } \\
\text { Interpersonal Helping }\end{array}$ & .575 & .032 & -.094 & -.523 & $.543 * *$ & $.669 * *$ & $1.098 * *$ & .126 & $.555 * *$ & $.429 *$ & .570 & $4<2=3<1$ \\
\hline $\begin{array}{l}\text { Union Citizenship Behaviors: } \\
\text { Union as an Organization }\end{array}$ & .583 & .106 & -.159 & -.460 & $.477 * *$ & $.742 * *$ & $1.043 * *$ & .265 & $.566 * *$ & .301 & .566 & $4<2<1,4=3 ; 2=3 ; 3<1$ \\
\hline
\end{tabular}

Note. ${ }^{*} \mathrm{p} \leq .05 ;{ }^{*} \mathrm{p} \leq .01$; the outcomes are estimated from factor scores with mean of 0 and a standard deviation of 1 , so that between profile differences can directly be interpreted in standard deviation units as effect size indicators. 
Online Supplemental Materials for:

\title{
Investigating the Dimensionality and Stability of Union Commitment Profiles Over a 10-
}

\author{
Year Period: A Latent Transition Analysis
}

\section{Sections}

1. Preliminary Confirmatory Factor Analyses.

2. Table S1. Goodness-of-Fit Statistics of the Longitudinal Confirmatory Factor Analytic (CFA) Models.

3. Table S2. Standardized Parameter Estimates from the Invariant Longitudinal Confirmatory Factor Analytic (CFA) Models.

4. Table S3. Latent Correlations and Composite Reliability from the Invariant Longitudinal Confirmatory Factor Analytic (CFA) Model: Union Commitment Measure.

5. Table S4. Latent Correlations and Composite Reliability from the Invariant Longitudinal Confirmatory Factor Analytic (CFA) Model: Predictors.

6. Table S5. Latent Correlations and Composite Reliability from the Invariant Longitudinal Confirmatory Factor Analytic (CFA) Model: Outcomes.

7. Table S6. Results from the Latent Profile Analysis Models Estimated Separately at Each Time Wave.

8. Figure S1. Elbow plot of the information criteria for the Latent Profile Analyses (Wave 1).

9. Figure S2. Elbow plot of the information criteria for the Latent Profile Analyses (Wave 2).

10.Figure S3. Elbow plot of the information criteria for the Latent Profile Analyses (Wave 3).

11.Table S7. Detailed results from the final Latent Transition Solution (Distributional Similarity)

12. Table S8. Results from the LTA models estimated using the subsample who completed at least two Time Waves $(N=404)$

13.Mplus Input to Estimate a 4-Class Latent Profile Analysis (Wave 1).

14.Mplus Input for Configural Similarity Model for a Latent Transition Analysis.

15.Mplus Input for Structural Similarity Model for a Latent Transition Analysis.

16.Mplus Input for Dispersion Similarity Model for a Latent Transition Analysis.

17.Mplus Input for Partial Dispersion Similarity Model for a Latent Transition Analysis.

18.Mplus Input for Distributional Similarity Model for a Latent Transition Analysis.

19.Mplus Input to Estimate a Latent Transition Analysis With Predictors Freely Estimated Across Time Waves and Profiles.

20.Mplus Input to Estimate a Latent Transition Analysis With Predictors Freely Estimated Across Time Waves.

21.Mplus Input to Estimate a Predictive Similarity Latent Transition Analysis.

22.Mplus Input to Estimate a Latent Transition Analysis With Outcomes Levels Freely Estimated Across Time Waves.

23.Mplus Input to Estimate a Explanatory Similarity Latent Transition Analysis. 


\section{Preliminary Confirmatory Factor Analyses}

Confirmatory factor analysis (CFA) models were estimated using Mplus 7.2 (Muthén and Muthén 2014). Due to the complexity of the measurement models underlying all constructs assessed in the present study and the relatively smaller sample size of employees who completed T2 and T3, these preliminary analyses were conducted separately for the union commitment measure, the predictors (union attitudes, union instrumentality, and union satisfaction), and the outcomes (union participation). These models were first estimated separately for each time point (T1: $n=637$; T2: $n=342$; T3: $n=$ 195). These models included three factors for the union commitment measure (loyalty to the union, responsibility to the union, and willingness to work for the union), four factors for the predictors (union attitudes; union instrumentality; union satisfaction: formal aspects and quality of union-member relationships), and two factors for the outcomes (union participation: UCB-I and UCB-O). Then, complete longitudinal models were estimated across all three time waves including nine factors for the union commitment measure (three factors $\mathrm{X}$ three time points), 14 factors for the predictors (four factors $\mathrm{X}$ three time points), and four factors for the outcomes (two factors $\mathrm{X}$ two time points). All models were specified as congeneric, with each item allowed to load on a single factor, and all factors freely allowed to correlate within and across time-points. In the union commitment model, one a priori correlated uniqueness was added to reflect the parallel wording of two items (If asked, I would serve on a committee..., and If asked, I would run for an elected office...). In the predictor model, a priori correlated uniquenesses were added to take into account the methodological artefact related to the negative wording of a subset of items. Finally, in all longitudinal models, a priori correlated uniquenesses between matching indicators of the factors utilized at the different time-points were also included to ensure that these longitudinal models did not converge on biased and inflated stability estimates (Jöreskog 1979; Marsh 2007). For all models, these correlated uniquenesses reflected the fact that unique variance of these indicators was known to emerge, in part, from shared sources of influences over time (e.g., Marsh, Abduljabbar, et al. 2013; Marsh, Scalas, et al. 2010)

CFA models for the union commitment measure and the predictors were estimated using the robust maximum Likelihood (MLR) estimator. This estimator provides standard errors and tests of fit that are robust in relation to non-normality and the use of ordered-categorical variables involving at least five response categories (Finney and DiStephano 2013). Longitudinal CFAs were conducted using the data from all respondents who completed at least one wave of data (corresponding to the T1 sample; $n=$ 637), using Full Information MLR estimation (FIML) — rather than a listwise deletion strategy focusing only on employees having answered two or three time points-(Enders 2010; Graham 2009). FIML estimation has been found to result in unbiased parameter estimates under even a very high level of missing data (e.g., 50\%), in the context of longitudinal studies with missing time points, under Missing At Random (MAR) assumptions, and even in some cases to violations of this assumption (e.g. Enders 2001; 2010; Enders and Bandalos 2001; Graham 2009; Larsen 2011; Shin, Davidson, and Long 2009). It should be noted that preliminary tests in which scores on all variables assessed at the earlier measurement point were used to predict attrition occurring at Time 2 or Time 3 revealed a single significant predictor of attrition: Participants with an initially higher level of willingness to work for the union were slightly more likely to have dropped out of the study by Time $3(b=-.700$, s.e. $=214, p \leq$ $.01)$. No other facet of union commitment or additional variable considered here predicted attrition. Still, this single statistically significant effect reinforces the importance of relying on missing data procedures relying on MAR assumption, and thus allowing missing values to be conditioned on earlier scores on this variable.

In contrast, because the union participation measure relies on a binary response scale, measurement models for the outcomes had to be estimated with a robust weight least square estimator using diagonal weight matrices (WLSMV), which has been found to outperform MLR estimation when response scales include 4 or less answer categories (Bandalos 2014; Beauducel and Herzberg 2006; Finney and DiStephano 2013; Flora and Curran 2004; Lei 2009; Rhemtulla, Brosseau-Liard, and Savalei 2012). A key limitation of WLSMV, when compared to MLR, has to do with the reliance on a slightly less efficient way of handling missing data (Asparouhov and Muthén 2010a). For this reason, factor scores were saved using starts value taken from the final retained WSLMV longitudinal model, but using a Bayes estimator which handles missing data in a manner comparable to FIML (Asparouhov and Muthén 2010b; Enders 2010). The reason why initial measurement models and tests of measurement invariance where not directly conducted with Bayes is to be able to properly assess the adequacy of the 
measurement model, and its measurement invariance over time, using typical goodness-of-fit information which are not available with Bayes.

Before saving the factor scores for our main analyses, we verified that the measurement model operated in the same manner across time waves, through sequential tests of measurement invariance (Millsap 2011): (1) configural invariance, (2) weak invariance (loadings), (3) strong invariance (loadings and intercepts/thresholds), (4) strict invariance (loadings, intercepts/thresholds and uniquenesses); (5) invariance of the latent variance-covariance matrix (loadings, intercepts/thresholds, uniquenesses, and latent variances and covariances); (6) latent means invariance (loadings, intercepts/thresholds, uniquenesses, latent variances and covariances, and latent means). In the outcomes model relying on WLSMV estimation, thresholds replace intercepts and reflect the points at which responses change from one answer category to another. However, in models based on binary items, it is not possible to separately test the invariance of the loadings and thresholds, so that steps 2 (weak) and 3 (strong) are combined into a single step of strong measurement invariance.

Given the known oversensitivity of the chi-square test of exact fit $\left(\chi^{2}\right)$ to sample size and minor model misspecifications (e.g., Marsh, Hau, and Grayson 2005), we relied on goodness-of-fit indices to describe the fit of the alternative models (Hu and Bentler 1999; Yu 2002): the comparative fit index (CFI), the Tucker-Lewis index (TLI), as well as the root mean square error of approximation (RMSEA) and its $90 \%$ confidence interval. Values greater than .90 for the CFI and TLI indicate adequate model fit, although values greater than .95 are preferable. Values smaller than .08 or .06 for the RMSEA respectively support acceptable and excellent model fit. Like the chi square, chi square difference tests present a known sensitivity to sample size and minor model misspecifications so that recent studies suggest complementing this information with changes in CFIs and RMSEAs (Chen 2007; Cheung and Rensvold 2002) in the context of tests of measurement invariance. A $\triangle$ CFI of .010 or less and a $\triangle$ RMSEA of .015 or less between a more restricted model and the preceding one indicate that the invariance hypothesis should not be rejected. It should be noted that with WLSMV, chi-square values are not exact, but rather adjusted or "estimated" to obtain a correct $p$-value. This explains why $\chi^{2}$ and CFI values can be non-monotonic with model complexity. This specificity is also important for the WLSMV $\chi^{2}$ difference tests, which need to be conducted via Mplus' DIFFTEST function (MD $\Delta \chi^{2}$; Asparouhov and Muthén 2006).

The results from these models are reported in supplementary Table S1. These results clearly support the a priori measurement models (at each time point separately, and longitudinally). For the union commitment measure, the results provided clear support to the complete longitudinal invariance of the model with none of the change in goodness-of-fit indices exceeding the recommended cut-off scores $(\Delta \mathrm{CFI} \leq .010 ; \Delta \mathrm{TLI} \leq .010 ; \Delta \mathrm{RMSEA} \leq .015$; and overlapping RMSEA confidence intervals). To ensure that the latent profiles estimated at each time wave were based on fully comparable measures of union commitment, the factor scores used in main analyses were saved from the model of complete measurement invariance (loadings, intercepts/thresholds, uniquenesses, latent variances and covariances, and latent means). Although only strict measurement invariance is required to ensure that measurement of the constructs remains equivalent across time waves for models based on factor scores (e.g., Millsap 2011), there are advantages to saving factors scores from a model of complete measurement invariance for use in latent profile analyses. Indeed, saving factor scores based on a measurement model in which both the variances and the latent means are invariant (i.e., respectively constrained to take a value of 1 and 0 in all time waves) provides scores on profile indicators that can be readily interpreted in standardized terms as deviation from the grand mean expressed in standard deviation units. However, for the predictors model, neither the strong $(\Delta \mathrm{CFI}=-.018 ; \Delta \mathrm{TLI} \leq-.019)$, nor the strict $(\Delta \mathrm{CFI}-.012 ; \Delta \mathrm{TLI}=-.011)$ measurement invariance was supported across time waves. Thus, in order to ensure comparability of the constructs across time waves, we pursued models of partial invariance (Byrne, Shavelson, and Muthén 1989), relaxing invariance constraints on five intercepts and three uniquenesses. In these models of partial invariance, each factor remained well-defined from a majority of invariant items. Furthermore, although the invariance of the latent means was supported by the data, it resulted in an unacceptable level of model fit according to the TLI $(<.900)$ so that factor scores were saved from the model of invariant latent variances and covariances. Finally, for the outcomes, the results supported the configural, strong, strict, and latent variance-covariance invariance of the model, but not the invariance of the latent means ( $\Delta \mathrm{CFI}-.019 ; \Delta \mathrm{TLI}=-.018$ ) so that factors scores were also saved from the model of invariant latent variances and covariances. For the predictors and 
outcomes, given that we are mainly interested in their relations with the profiles, latent mean invariance does not provide any advantage in terms of interpretation.

The parameter estimates from these models are reported in Tables S2 to S5. These parameter estimates were used to compute composite reliability coefficients associated with each of the a priori factors using McDonald (1970) omega ( $\omega)$ coefficient:

$$
\omega=\frac{\left(\sum\left|\lambda_{i}\right|\right)^{2}}{\left[\left(\sum\left|\lambda_{i}\right|\right)^{2}+\sum \delta_{i}\right]}
$$

where $\left|\lambda_{i}\right|$ are the standardized factor loadings associated with a factor in absolute values, and $\delta i$, the item uniquenesses. The numerator, were the factor loadings are summed, and then squared, reflects the proportion of the variance in in indicators that reflect true score variance, whereas the denominator reflects total amount of variance in the items including both true score variance and random measurement errors (reflects by the sum of the items uniquenesses associated with a factor). These coefficients are all satisfactory $(\omega=.710$ to $.925 ; M=.828)$, and reported in Tables S3 to S5.

\section{References used in this supplement}

Asparouhov, Tihomir, and Bengt O. Muthén. 2006. Robust chi-square difference testing with mean and variance adjusted test statistics. Los Angeles, CA: Muthén \& Muthén; www.statmodel.com/examples/webnote.shtml\#web10

Asparouhov, Tihomir, and Bengt O. Muthén. 2010a. Weighted Least Square estimation with missing data. www.statmodel.com/download/GstrucMissingRevision.pdf

Asparouhov, Tihomir, and Bengt O. Muthén. 2010b. Bayesian analysis of latent variable models using Mplus. http://statmodel2.com/download/BayesAdvantages6.pdf

Bandalos, Deborah L. 2014. Relative performance of categorical diagonally weighted least squares and robust maximum likelihood estimation. Structural Equation Modeling 21(1): 102-116.

Beauducel, Andre, and Philipp Y. Herzberg. 2006. On the Performance of Maximum Likelihood Versus Means and Variance Adjusted Weighted Least Squares Estimation in CFA. Structural Equation Modeling 13(2): 186-203.

Byrne, Barbata M., Richard J. Shavelson, and Bengt O. Muthén. 1989. Testing for the equivalence of factor covariance and means structures: The issue of partial measurement invariance. Psychological Bulletin 105(3): 456-466.

Chen, Fang F. 2007. Sensitivity of goodness of fit indexes to lack of measurement. Structural Equation Modeling 14(3): 464-504.

Cheung, Gordon W., and Roger B. Rensvold. 2002. Evaluating goodness-of fit indexes for testing measurement invariance. Structural Equation Modeling 9(2): 233-255.

Enders, Craig K. 2001. The impact of nonnormality on full information maximum-likelihood estimation for structural equation models with missing data. Psychological Methods 6(4): 352-370.

Enders, Craig K. 2010. Applied missing data analysis. New York: Guilford.

Enders, Craig K., and Deborah L. Bandalos. 2001. The relative performance of full information maximum likelihood estimation for missing data in structural equation models. Structural Equation Modeling 8(3): 430-457.

Finney, Sara J., and Christine DiStefano. 2013. Non-normal and categorical data in structural equation modeling. In Gregory R. Hancock, Ralph O. Mueller (Eds), Structural Equation Modeling: A Second Course, $2^{\text {nd }}$ edition (pp. 439-492). Greenwich, CO: IAP.

Flora, David B., and Patrick J. Curran. 2006. An empirical evaluation of alternative methods of estimation for confirmatory factor analysis with ordinal data. Psychological Methods 9(4): 466491.

Graham, John W. 2009. Missing data analysis: Making it work in the real world. Annual Review of Psychology 60: 549-576.

Hu, Li-Tze., and Peter M. Bentler. 1999. Cutoff criteria for fit indexes in covariance structure analysis: Conventional criteria versus new alternatives. Structural Equation Modeling 6(1): 1-55.

Joreskög, Karl G. 1973. A general method for estimating a linear structural equation system. In A.S. Golberger, \& O.D. Duncan (Eds.), Structural equation models in the social sciences (pp. 85112). New York, NY: Seminar.

Lei, Pui-Wa. 2009. Evaluating estimation methods for ordinal data in structural equation modeling. Quality \& Quantity 43(3): 495-507. 
Marsh, Herbert. W. 2007. Self-concept theory, measurement and research into practice: The role of self-concept in educational psychology. Leicester, UK: British Psychological Society.

Marsh, Herbert. W., Adel S. Abduljabbar, Maher Abu-Hilal, Alexandre J. S. Morin, Faisal Abdelfattah, Kim C. Leung, Man K. Xu, Benjamin Nagengast, and Philip Parker. 2013. Factor structure, discriminant and convergent validity of TIMSS math and science motivation measures: A comparison of USA and Saudi Arabia. Journal of Educational Psycholog 105(1): 108-128.

Marsh, Herbert W., Kit-Tai Hau, and David Grayson. 2005. Goodness of Fit in Structural Equation Models. In Maydeu-Olivares, Albert (Ed); McArdle, John J. (Ed), Contemporary psychometrics: A festschrift for Roderick P. McDonald. (pp. 275-340). Mahwah, NJ, US: Lawrence Erlbaum Associates Publishers.

Marsh, Herbert W., Francesca L. Scalas, and Benjamin Nagengast. 2010. Longitudinal tests of competing factor structures for the Rosenberg self-esteem scale: Traits, ephemeral artifacts, and stable response styles. Psychological Assessment 22(2): 366-381.

McDonald, R.P. 1970. Theoretical foundations of principal factor analysis, canonical factor analysis, and alpha factor analysis. British Journal of Mathematical \& Statistical Psychology, 23(1): 1-21.

Millsap, Roger E. 2011. Statistical approaches to measurement invariance. NewYork, NY: Taylor \& Francis.

Muthén, Linda K., and Muthén, Bengt O. 2014. Mplus user's guide. Los Angeles: Muthén \& Muthén.

Shin, Tacksoo, Mark L. Davidson, and Jeffrey D. Long. 2009. Effects of missing data methods in structural equations modeling with nonnormal data. Structural Equation Modeling 16(1): 70-98.

Rhemtulla, Mijke, Patricia É. Brosseau-Liard, and Victoria Savalei. 2012. When can categorical variables be treated as continuous? A comparison of robust continuous and categorical SEM estimation methods under suboptimal conditions. Psychological Methods 17(3): 354-373.

Yu, Ching-Yun. 2002. Evaluating cutoff criteria of model fit indices for latent variable models with binary and continuous outcomes. Los Angeles, CA: University of California. 
Table S1.

Goodness-of-Fit Statistics of the Longitudinal Confirmatory Factor Analytic (CFA) Models

\begin{tabular}{|c|c|c|c|c|c|c|c|c|c|}
\hline Description & $\chi^{2}(d f)$ & CFI & TLI & RMSEA & $90 \% \mathrm{CI}$ & $\Delta \chi^{2}(d f)$ & $\Delta \mathrm{CFI}$ & $\Delta \mathrm{TLI}$ & $\triangle \mathrm{RMSEA}$ \\
\hline \multicolumn{10}{|l|}{ Union Commitment } \\
\hline Time 1 & $122.841 *(61)$ & .971 & .963 & .040 & {$[.030, .050]$} & - & - & - & - \\
\hline Time 2 & $121.994 *(61)$ & .923 & 902 & .054 & {$[.040, .068]$} & - & - & - & - \\
\hline Time 3 & $125.870 *(61)$ & .957 & .945 & .074 & {$[.056, .093]$} & - & - & - & - \\
\hline Configural invariance & $1004.110 *(624)$ & .936 & .925 & .031 & {$[.027, .034]$} & - & - & - & - \\
\hline Weak Invariance & $1036.572 *(644)$ & .934 & .924 & .031 & {$[.027, .034]$} & $32.418 *(20)$ & -.002 & -.001 & .000 \\
\hline Strong Invariance & $1110.748 *(664)$ & .925 & .917 & .032 & {$[.029, .036]$} & $80.202 *(20)$ & -.009 & -.007 & +.001 \\
\hline Strict Invariance & $1206.262 *(690)$ & .915 & .908 & .034 & {$[.031, .037]$} & $65.580 *(26)$ & -.010 & -.009 & +.002 \\
\hline Variance-Covariance Invariance & $1251.901 *(702)$ & .908 & .903 & .035 & {$[.032, .038]$} & $39.372 *(12)$ & -.007 & -.005 & +.001 \\
\hline Latent Mean Invariance & $1290.137 *(708)$ & .903 & .900 & .036 & {$[.033, .039]$} & $42.752 *(6)$ & -.005 & -.003 & +.001 \\
\hline \multicolumn{10}{|l|}{ Predictors } \\
\hline Time 1 & $260.181 *(123)$ & .962 & .952 & .042 & {$[.035, .049]$} & - & - & - & - \\
\hline Time 2 & $238.710 *(123)$ & .948 & .935 & .053 & {$[.043, .062]$} & - & - & - & - \\
\hline Time 3 & $181.800 *(123)$ & .960 & .951 & .050 & {$[.033, .064]$} & - & - & - & - \\
\hline Configural invariance & $1915.836 *(1239)$ & .928 & .917 & .029 & {$[.027, .032]$} & - & - & - & - \\
\hline Weak Invariance & $1946.784 *(1267)$ & .928 & .919 & .029 & {$[.026, .032]$} & $32.047(28)$ & .000 & +.002 & .000 \\
\hline Strong Invariance & $2147.826 *(1295)$ & .910 & .900 & .032 & {$[.030, .035]$} & $217.419 *(28)$ & -.018 & -.019 & +.003 \\
\hline Strong Partial Invariance & $2018.047 *(1285)$ & .922 & .913 & .030 & {$[.027, .032]$} & $73.832 *(18)$ & -.006 & -.006 & +.001 \\
\hline Strict Invariance & $2171.675 *(1321)$ & .910 & .902 & .032 & {$[.029, .034]$} & $134.984 *(36)$ & -.012 & -.011 & +.002 \\
\hline Strict Partial Invariance & $2117.950 *(1315)$ & .915 & .907 & .031 & {$[.029, .033]$} & $89.608 *(30)$ & -.007 & -.006 & +.001 \\
\hline Variance-Covariance Invariance & $2182.989 *(1335)$ & .910 & .904 & .032 & {$[.029, .034]$} & $60.915 *(20)$ & -.005 & -.003 & +.001 \\
\hline Latent Mean Invariance & $2268.078 *(1343)$ & .902 & .896 & .033 & {$[.031, .035]$} & $79.064 *(8)$ & -.008 & -.008 & +.001 \\
\hline \multicolumn{10}{|l|}{ Outcomes } \\
\hline Time 2 & $117.710 *(64)$ & .953 & .942 & .050 & {$[.035, .064]$} & - & - & - & - \\
\hline Time 3 & $88.218 *(64)$ & .980 & .976 & .044 & {$[.017-.065]$} & - & - & - & - \\
\hline Configural Invariance & $343.809 *(293)$ & .975 & .973 & .021 & {$[.009, .029]$} & - & - & - & - \\
\hline Strong Invariance & $365.175 *(302)$ & .969 & .967 & .023 & {$[.013, .031]$} & $27.765 * *(9)$ & -.006 & -.006 & +.002 \\
\hline Strict Invariance & $372.877 *(315)$ & .972 & .971 & .021 & {$[.010, .030]$} & $12.347(13)$ & +.003 & +.004 & -.002 \\
\hline Variance-Covariance Invariance & $380.085 *(318)$ & .970 & .969 & .022 & {$[.012, .030]$} & $6.026(3)$ & -.002 & -.002 & +.001 \\
\hline Latent Mean Invariance & $420.173 *(320)$ & .951 & .951 & .028 & {$[.020, .035]$} & $29.716 * *(2)$ & -.019 & -.018 & +.006 \\
\hline
\end{tabular}

Note. ${ }^{*} p<.01 ; \chi^{2}=$ chi-square test of exact fit; $d f=$ degrees of freedom; CFI = comparative fit index; TLI = Tucker-Lewis index; RMSEA = root mean square error of approximation; $90 \% \mathrm{CI}=90 \%$ confidence interval of the RMSEA; $\Delta \chi^{2}=$ Chi-square difference test. 


\section{Supplementary Table S2}

Standardized Parameter Estimates from the Invariant Longitudinal Confirmatory Factor Analytic (CFA) Models

\begin{tabular}{|c|c|c|c|c|c|c|}
\hline & \multicolumn{2}{|c|}{ Union Commitment } & \multicolumn{2}{|c|}{ Predictors } & \multicolumn{2}{|c|}{ Outcomes } \\
\hline & Loading $(\lambda)$ & Uniqueness $(\delta)$ & $\lambda$ & $\delta$ & $\lambda$ & $\delta$ \\
\hline \multicolumn{3}{|l|}{ Loyalty } & \multicolumn{2}{|c|}{ Union Attitude } & \multicolumn{2}{|c|}{ Participation: $U C B-O$} \\
\hline Item 1 & .775 & .302 & .671 & .549 & .687 & .528 \\
\hline Item 3 & .778 & .225 & .489 & .761 & .466 & .783 \\
\hline Item 4 & .794 & .222 & .709 & .497 & .713 & .491 \\
\hline Item 5 & .755 & .422 & .712 & .493 & .750 & .465 \\
\hline Item 7 & & & & & .741 & .451 \\
\hline Item 8 & & & & & .899 & .192 \\
\hline Item 9 & & & & & .734 & .461 \\
\hline \multicolumn{3}{|c|}{ Responsibility } & \multicolumn{2}{|c|}{ Union Instrumentality } & \multicolumn{2}{|c|}{ Participation: $U C B-I$} \\
\hline Item 1 & .656 & .382 & .557 & .690 & .847 & .283 \\
\hline Item 2 & .697 & .366 & .625 & .610 & .839 & .297 \\
\hline Item 1 & .757 & .276 & .760 & .423 & & \\
\hline Item 2 & .672 & .405 & .806 & $.350 / .443 / .559$ & & \\
\hline Item 3 & .645 & .562 & .774 & .401 & & \\
\hline \multicolumn{3}{|l|}{ Item 4} & .667 & $.555 / .554 / .682$ & & \\
\hline \multicolumn{7}{|c|}{ Satisfaction: Relationships } \\
\hline \multicolumn{3}{|l|}{ Item 1} & .812 & .341 & & \\
\hline \multicolumn{3}{|l|}{ Item 2} & .734 & .462 & & \\
\hline \multicolumn{3}{|l|}{ Item 3} & .764 & $.417 / .509 / .470$ & & \\
\hline \multicolumn{3}{|l|}{ Item 4} & .838 & .298 & & \\
\hline \multicolumn{3}{|l|}{ Item 5} & .808 & .347 & & \\
\hline
\end{tabular}

Note. All loadings and uniquenesses are significant $(p<.01)$. Values for the non-invariant uniquenesses are reported sequentially for Times $1-2-3 ; \mathrm{UCBI}=$ union citizenship behaviors: interpersonal helping; $\mathrm{UCBO}=$ union citizenship behaviors: union as an organization; 
Supplementary Table S3

Latent Correlations and Composite Reliability from the Invariant Longitudinal Confirmatory Factor Analytic (CFA) Model: Union Commitment Measure.

\begin{tabular}{|c|c|c|c|c|c|c|c|c|c|}
\hline & UCL1 & UCR1 & UCWW1 & UCL2 & UCR2 & UCWW2 & UCL3 & UCR3 & UCWW3 \\
\hline UCL1 & .925 & & & & & & & & \\
\hline UCR1 & $.648 * *$ & .830 & & & & & & & \\
\hline UCWW1 & $.768 * *$ & $.575^{* *}$ & .776 & & & & & & \\
\hline UCL2 & $.660 * *$ & $.479 * *$ & $.464 * *$ & .925 & & & & & \\
\hline UCR2 & $.388 * *$ & $.593 * *$ & $.331 * *$ & $.648 * *$ & .830 & & & & \\
\hline UCWW2 & $.483 * *$ & $.392 * *$ & $.618 * *$ & $.768 * *$ & $.575^{* *}$ & .776 & & & \\
\hline UCL3 & $.341 * *$ & $.273 * *$ & $.188^{*}$ & $.414 * *$ & $.193 * *$ & $.342 * *$ & .925 & & \\
\hline UCR3 & .116 & $.252 *$ & .087 & .154 & $.212 *$ & .112 & $.648 * *$ & .830 & \\
\hline UCWW3 & $.215^{*}$ & $.231 *$ & $.448 * *$ & .119 & .065 & $.459 * *$ & $.768 * *$ & $.575 * *$ & .776 \\
\hline
\end{tabular}

Note. ${ }^{*} p<.05 ; * *<.01 ; \mathrm{UCL}=$ union commitment: union loyalty; UCR $=$ union commitment: responsibility to the union; UCWW $=$ union commitment: willingness to work for the union; $1=$ time $1 ; 2=$ time $2 ; 3=$ time 3 ; composite reliability scores reported in the diagonal (italicized).

\section{Supplementary Table S4}

Latent Correlations and Composite Reliability from the Invariant Longitudinal Confirmatory Factor Analytic (CFA) Model: Predictors.

\begin{tabular}{|c|c|c|c|c|c|c|c|c|c|c|c|c|}
\hline & UA1 & UI1 & USF1 & USR1 & UA2 & UI2 & USF2 & USR2 & UA3 & UI3 & USF3 & USR3 \\
\hline UA1 & .776 & & & & & & & & & & & \\
\hline UI1 & $.730 * *$ & .710 & & & & & & & & & & \\
\hline USF1 & $.537 * *$ & $.723 * *$ & .839 & & & & & & & & & \\
\hline USR 1 & $.554 * *$ & $.727 * *$ & $.863 * *$ & .894 & & & & & & & & \\
\hline UA2 & $.584 * *$ & $.540 * *$ & $.346^{* *}$ & $.345 * *$ & .776 & & & & & & & \\
\hline UI2 & $.622 * *$ & $.716^{* * *}$ & $.552 * *$ & $.496 * *$ & $.730 * *$ & .710 & & & & & & \\
\hline USF2 & $.352 * *$ & $.431 * *$ & $.576^{* * *}$ & $.501 * *$ & $.537 * *$ & $.723 * *$ & .832 & & & & & \\
\hline USR2 & $.402 * *$ & $.457 * *$ & $.258 * *$ & $.326^{* *}$ & $.554 * *$ & $.727 * *$ & $.863^{* *}$ & .889 & & & & \\
\hline UA3 & $.438 * *$ & $.385^{* *}$ & .153 & .152 & $.507 * *$ & $.599 * *$ & $.310 * *$ & $.258 * *$ & .776 & & & \\
\hline UI3 & $.226 * *$ & $.447 * *$ & $.371 * *$ & $.314^{* *}$ & $.379 * *$ & $.548 * *$ & $.392 * *$ & $.326^{* *}$ & $.730 * *$ & .710 & & \\
\hline USF3 & $.323 * *$ & $.375^{* *}$ & $.328 * *$ & $.377 * *$ & $.328 * *$ & $.377 * *$ & $.398 * *$ & $.315^{* *}$ & $.537 * *$ & $.723 * *$ & .814 & \\
\hline USR3 & $.214 * *$ & $.330 * *$ & $.314 * *$ & $.464 * *$ & $.314 * *$ & $.464 * *$ & $.303 * *$ & $.335^{* *}$ & $.554 * *$ & $.727 * *$ & $.863 * *$ & .891 \\
\hline
\end{tabular}

Note. $* p<.05 ; * * p<.01 ; \mathrm{UA}=$ union attitudes; UI = union instrumentality; USF $=$ union satisfaction: formal; USR = union satisfaction: relationships; $1=$ time $1 ; 2=$ time $2 ; 3=$ time 3 ; Composite reliability scores reported in the diagonal (italicized). 


\section{Supplementary Table S5}

Latent Correlations and Composite Reliability from the Invariant Longitudinal Confirmatory Factor Analytic (CFA) Model: Outcomes.

\begin{tabular}{lllll}
\hline & UCBI2 & UCBO2 & UCBI3 & UCBO3 \\
\hline UCBI2 & .884 & & & \\
UCBO2 & $.887 * *$ & .890 & & \\
UCBI3 & $.359^{* *}$ & $.359 * *$ & .884 & \\
UCBO3 & $.331^{*}$ & $.594 * *$ & $.887 * *$ & .890
\end{tabular}

Note. $* p<.05 ; * *<.01 ; \mathrm{UCBI}=$ union citizenship behaviors: interpersonal helping; $\mathrm{UCBO}=$ union citizenship behaviors: union as an organization; $2=$ time $2 ; 3=$ time 3 ; Composite reliability scores reported in the diagonal (italicized). 
Supplementary Table S6

Results from the Latent Profile Analysis Models Estimated Separately at Each Time Wave.

\begin{tabular}{|c|c|c|c|c|c|c|c|c|c|c|}
\hline Model & LL & $\# f p$ & Scaling & $\mathrm{AIC}$ & CAIC & $\mathrm{BIC}$ & $\mathrm{ABIC}$ & Entropy & aLMR & BLRT \\
\hline \multicolumn{11}{|c|}{ Time 1 (n=637) } \\
\hline 1 Profile & -2407.584 & 6 & 1.068 & 4827.169 & 4859.909 & 4853.909 & 4834.860 & $\mathrm{Na}$ & $\mathrm{Na}$ & $\mathrm{Na}$ \\
\hline 2 Profiles & -2101.009 & 13 & 1.602 & 4228.018 & 4298.956 & 4285.956 & 4244.682 & .760 & .022 & $\leq .001$ \\
\hline 3 Profiles & -1845.235 & 20 & 1.278 & 3730.470 & 3839.606 & 3819.606 & 3756.107 & .835 & $\leq .001$ & $\leq .001$ \\
\hline 4 Profiles & -1752.716 & 27 & 1.452 & 3559.432 & 3706.765 & 3679.765 & 3594.042 & .842 & .226 & $\leq .001$ \\
\hline 5 Profiles & -1679.283 & 34 & 1.121 & 3426.566 & 3612.096 & 3578.096 & 3470.149 & .838 & $\leq .001$ & $\leq .001$ \\
\hline 6 Profiles & -1646.935 & 41 & 1.187 & 3375.869 & 3599.597 & 3558.597 & 3428.425 & .851 & .191 & $\leq .001$ \\
\hline 7 Profiles & -1626.790 & 48 & 1.267 & 3349.581 & 3611.506 & 3563.506 & 3411.109 & .825 & .527 & .020 \\
\hline 8 Profiles & -1613.636 & 55 & 1.066 & 3337.272 & 3637.394 & 3582.394 & 3407.773 & .827 & .008 & .040 \\
\hline \multicolumn{11}{|c|}{ Time $2(n=342)$} \\
\hline 1 Profile & -1349.447 & 6 & 1.310 & 2710.894 & 2739.903 & 2733.903 & 2714.869 & $\mathrm{Na}$ & $\mathrm{Na}$ & $\mathrm{Na}$ \\
\hline 2 Profiles & -1173.355 & 13 & 1.446 & 2372.711 & 2435.563 & 2422.563 & 2381.325 & .828 & .004 & $\leq .001$ \\
\hline 3 Profiles & -1049.680 & 20 & 1.280 & 2139.361 & 2236.057 & 2216.057 & 2152.612 & .862 & $\leq .001$ & $\leq .001$ \\
\hline 4 Profiles & -1000.311 & 27 & 1.264 & 2054.623 & 2185.162 & 2158.162 & 2072.512 & .842 & .010 & $\leq .001$ \\
\hline 5 Profiles & -974.704 & 34 & 1.141 & 2017.408 & 2181.791 & 2147.791 & 2039.936 & .848 & .037 & $\leq .001$ \\
\hline 6 Profiles & -948.024 & 41 & 1.100 & 1978.047 & 2176.274 & 2135.274 & 2005.213 & .835 & .008 & $\leq .001$ \\
\hline 7 Profiles & -928.725 & 48 & 1.004 & 1953.451 & 2185.521 & 2137.521 & 1985.255 & .852 & .064 & $\leq .001$ \\
\hline 8 Profiles & -907.347 & 55 & 0.933 & 1924.695 & 2190.609 & 2135.609 & 1961.137 & .862 & .008 & .126 \\
\hline \multicolumn{11}{|c|}{ Time $3(n=195)$} \\
\hline 1 Profile & -876.815 & 6 & 1.152 & 1765.631 & 1791.269 & 1785.269 & 1766.262 & $\mathrm{Na}$ & $\mathrm{Na}$ & $\mathrm{Na}$ \\
\hline 2 Profiles & -749.991 & 13 & 1.101 & 1525.983 & 1581.532 & 1568.532 & 1527.350 & .828 & $\leq .001$ & $\leq .001$ \\
\hline 3 Profiles & -659.728 & 20 & 1.132 & 1359.456 & 1444.916 & 1424.916 & 1361.559 & .898 & .002 & $\leq .001$ \\
\hline 4 Profiles & -607.336 & 27 & 1.100 & 1268.672 & 1384.043 & 1357.043 & 1271.511 & .926 & .082 & $\leq .001$ \\
\hline 5 Profiles & -584.936 & 34 & 1.133 & 1237.873 & 1383.155 & 1349.155 & 1241.448 & .877 & .181 & .010 \\
\hline 6 Profiles & -563.455 & 41 & .986 & 1208.909 & 1384.102 & 1343.102 & 1213.221 & .885 & .050 & $\leq .001$ \\
\hline 7 Profiles & -547.276 & 48 & .983 & 1190.552 & 1395.656 & 1347.656 & 1195.599 & .899 & .190 & $\leq .001$ \\
\hline 8 Profiles & -532.372 & 55 & .965 & 1174.744 & 1409.759 & 1354.759 & 1180.527 & .905 & .201 & .051 \\
\hline
\end{tabular}

Note. LL = model loglikelihood; \#fp = number of free parameters; scaling = scaling correction factor associated with robust maximum likelihood estimates; $\mathrm{AIC}=$ Akaike information criteria; CAIC = constant AIC; BIC = Bayesian information criteria; ABIC = sample size adjusted BIC; aLMR = adjusted LoMendel-Rubin likelihood ratio test; BLRT = bootstrap likelihood ratio test. 


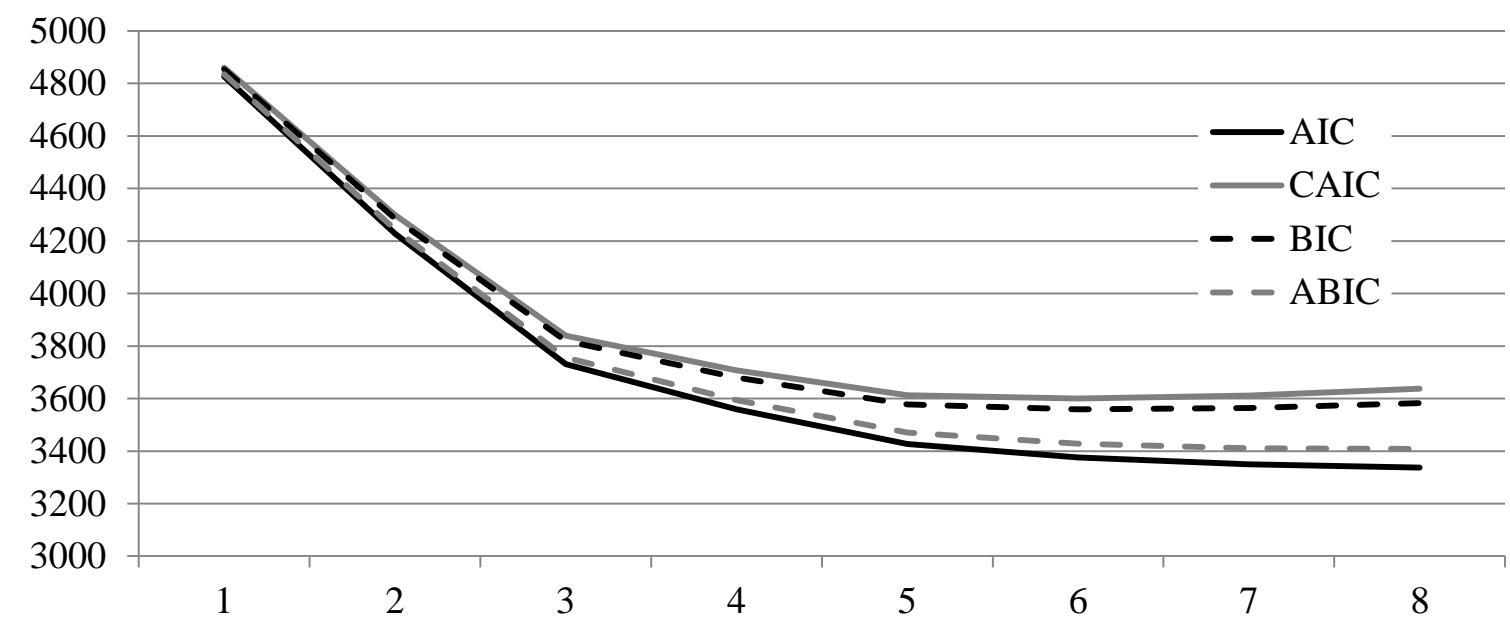

Figure S1. Elbow Plot of the Information Criteria for the Latent Profile Analyses (Time 1).

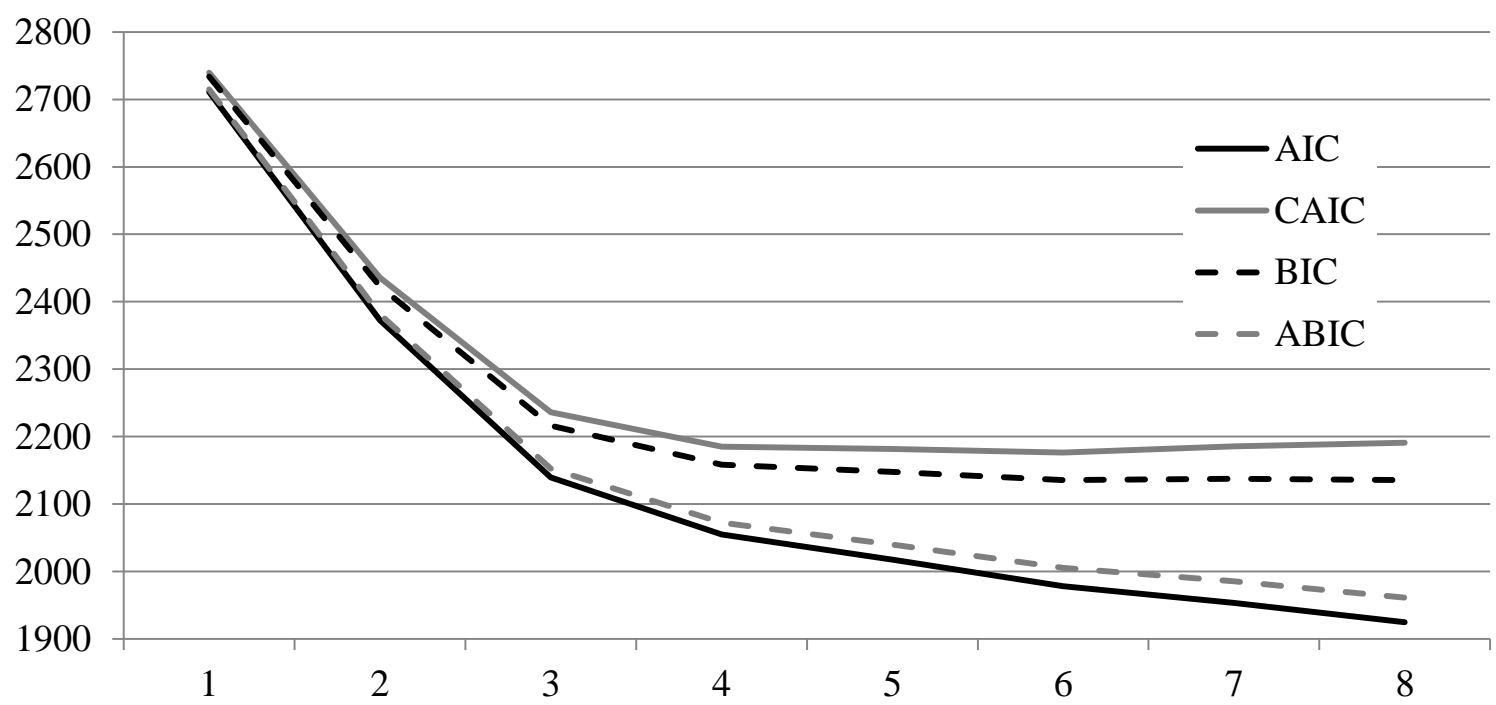

Figure S2. Elbow Plot of the Information Criteria for the Latent Profile Analyses (Time 2).

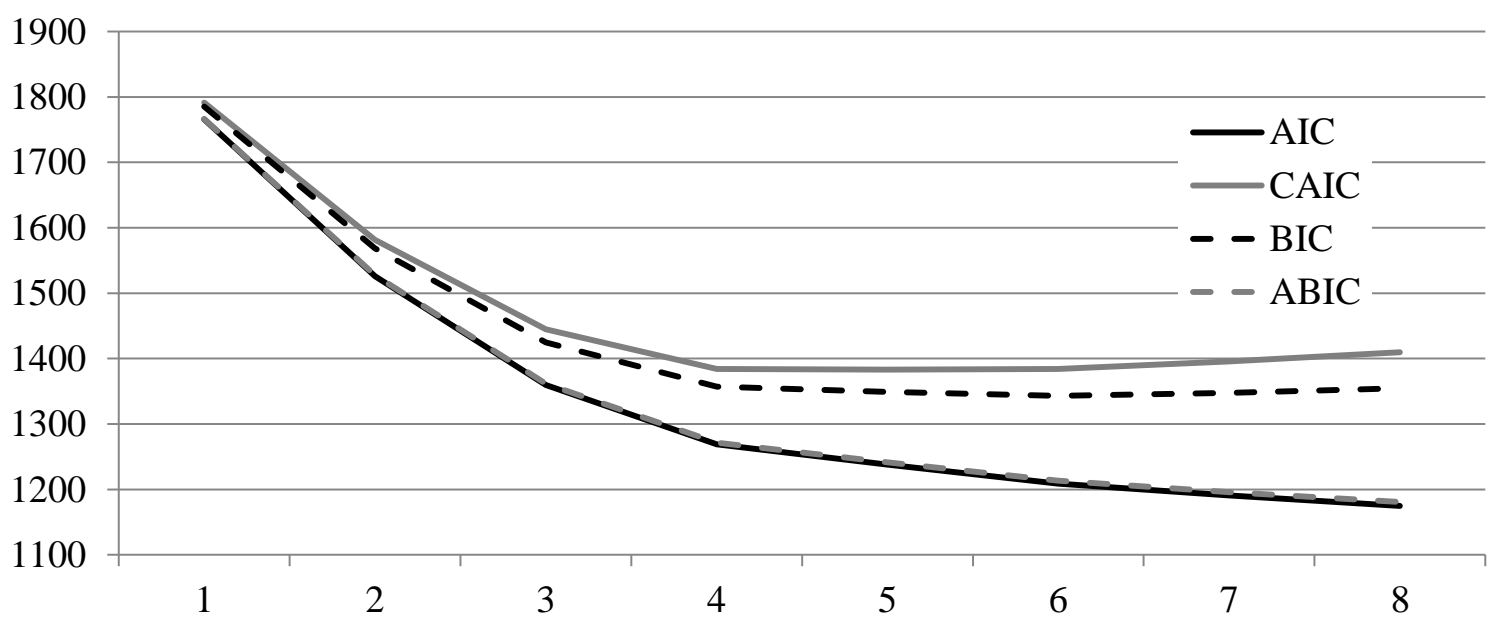

Figure S3. Elbow Plot of the Information Criteria for the Latent Profile Analyses (Time 3). 


\section{Supplementary Table S7}

Detailed Results from the Final Latent Transition Solution (Partial Dispersion Similarity)

\begin{tabular}{|c|c|c|c|c|c|c|c|c|c|}
\hline & \multirow[b]{2}{*}{ Waves } & \multicolumn{2}{|c|}{ Profile 1} & \multicolumn{2}{|c|}{ Profile 2} & \multicolumn{2}{|c|}{ Profile 3} & \multicolumn{2}{|c|}{ Profile 4} \\
\hline & & Mean & CI & Mean & CI & Mean & CI & Mean & CI \\
\hline Loyalty to the Union & Similar & 1.031 & $0.915 ; 1.146$ & 0.231 & $0.149 ; 0.314$ & -0.327 & $-0.446 ;-0.209$ & -1.365 & $-1.577 ;-1.152$ \\
\hline Responsibility to the Union & Similar & 0.853 & $0.739 ; 0.967$ & 0.106 & $0.056 ; 0.156$ & -0.178 & $-0.242 ;-0.114$ & -1.088 & $-1.275 ;-0.902$ \\
\hline \multirow[t]{2}{*}{ Willingness to Work for the Union } & Similar & 0.931 & $0.799 ; 1.062$ & 0.199 & $0.087 ; 0.312$ & -0.312 & $-0.422 ;-0.202$ & -1.187 & $-1.353 ;-1.021$ \\
\hline & & Variance & $\mathrm{CI}$ & Variance & $\mathrm{CI}$ & Variance & $\mathrm{CI}$ & Variance & $\mathrm{CI}$ \\
\hline \multirow[t]{2}{*}{ Loyalty to the Union } & Wave $1 \& 2$ & 0.158 & $0.116 ; 0.201$ & 0.068 & $0.044 ; 0.092$ & 0.139 & $0.109 ; 0.169$ & 0.377 & $0.264 ; 0.491$ \\
\hline & Wave 3 & 0.277 & $0.167 ; 0.386$ & 0.046 & $0.032 ; 0.059$ & 0.085 & $0.063 ; 0.108$ & 0.860 & $0.514 ; 1.205$ \\
\hline \multirow[t]{2}{*}{ Responsibility to the Union } & Wave $1 \& 2$ & 0.311 & $0.213 ; 0.410$ & 0.116 & $0.057 ; 0.174$ & 0.288 & $0.192 ; 0.383$ & 0.623 & $0.456 ; 0.790$ \\
\hline & Wave 3 & 0.343 & $0.254 ; 0.431$ & 0.024 & $0.018 ; 0.03$ & 0.045 & $0.029 ; 0.061$ & 1.135 & $0.630 ; 1.640$ \\
\hline \multirow[t]{2}{*}{ Willingness to Work for the Union } & Wave $1 \& 2$ & 0.372 & $0.241 ; 0.502$ & 0.099 & $0.073 ; 0.125$ & 0.129 & $0.074 ; 0.184$ & 0.263 & $0.183 ; 0.343$ \\
\hline & Wave 3 & 0.539 & $0.361 ; 0.718$ & 0.130 & $0.098 ; 0.162$ & 0.168 & $0.117 ; 0.218$ & 0.689 & $0.325 ; 1.053$ \\
\hline
\end{tabular}

Note. $\mathrm{CI}=95 \%$ confidence interval. 
Mplus Input to Estimate a 4-Class Latent Profile Analysis (Wave 1)

! In all input files, statements preceded by! are annotations.

! Use the following statement to identify the data set. Here, the data set is labelled Unionprofile.dat.

DATA:

FILE IS Unionprofile.dat;

! The variables names function identifies all variables in the data set, in order of appearance,

! whereas the usevariable command identifies the variables used in the analysis.

VARIABLE:

NAMES = ID UCL1 UCR1 UCW1 UCL2 UCR2 UCW2 UCL3 UCR3 UCW3

BIGL1 UNINST1 BIGL2 UNINST2 BIGL3 UNINST3 SFA1 SQUMR1 SFA2 SQUMR2 SFA3 SQUMR3

UCBI2 UCBO2 UCBI3 UCBO3;

USEVARIABLES = UCL1 UCR1 UCW1;

! The following identifies the unique identifier for participants

IDVARIABLE = ID;

! The following identifies the number of latent profiles requested in the analysis.

CLASSES = c (4);

Analysis:

TYPE $=$ MIXTURE ;

ESTIMATOR $=$ MLR;

! The following set up is to estimate the model using 3 processors, 3000 starts values, 100 final stage optimizations, and 100 iterations.

process $=3$;

STARTS $=3000100$

STITERATIONS $=100$;

! In this input, the overall model statement defines sections that are common across profiles.

! Here, there is no need to include anything in this section.

! The \%c\#1\% to \%c\#5\% sections are class-specific statement to specify which part of the

$!$ model is freely estimated in each profile.

! For a simple latent profile model, include the means of the indicators (using []) in all profiles.

! To also freely estimate all variances, add the following in each class-specific statement:

! UCL1 UCRI UCW1;

MODEL:

$\%$ OVERALL $\%$

$\% \mathrm{c} \# 1 \%$

[UCL1 UCR1 UCW1];

UCL1 UCR1 UCW1;

$\% \mathrm{c \#} 2 \%$

[UCL1 UCR1 UCW1];

UCL1 UCR1 UCW1;

$\% \mathrm{c \# 3 \%}$

[UCL1 UCR1 UCW1];

UCL1 UCR1 UCW1;

$\% \mathrm{c \#} \%$

[UCL1 UCR1 UCW1];

UCL1 UCR1 UCW1;

! Specific sections of output are requested. TECH11 estimates LMR, and TECH14 estimates BLRT.

OUTPUT: STDYX SAMPSTAT CINTERVAL MODINDICES (10) SVALUES

RESIDUAL TECH1 TECH7 TECH11 TECH13 TECH14; 
Mplus Input to Estimate a Configural Similarity Model for a Longitudinal Latent Profile Analysis ! Annotations only focus on functions not previously defined.

DATA:

FILE IS Unionprofile.dat;

VARIABLE:

NAMES = ID UCL1 UCR1 UCW1 UCL2 UCR2 UCW2 UCL3 UCR3 UCW3

BIGL1 UNINST1 BIGL2 UNINST2 BIGL3 UNINST3 SFA1 SQUMR1 SFA2 SQUMR2 SFA3 SQUMR3

UCBI2 UCBO2 UCBI3 UCBO3;

USEVARIABLES = UCL1 UCR1 UCW1 UCL2 UCR2 UCW2 UCL3 UCR3 UCW3;

IDVARIABLE = ID;

! The following identifies the number of latent profiles (4) requested in the analysis

! One latent profile variable $(c 1, c 2, c 3)$ is required for each specific time wave.

CLASSES = c1 (4) c2 (4) c3 (4);

Analysis:

TYPE = MIXTURE ; ESTIMATOR = MLR;

process $=3$;

STARTS = 10000 500; STITERATIONS = 1000;

! In this input, the statements included in the overall model statement indicates that employees can

! make a transition from one profile to the other across adjacent time points.

! Then, subsections corresponding to the various latent profile variables (one per time waves;

! MODEL Cl to C3).

! The labels in parentheses are used to impose equality constraints on parameters (parameters

! with the same labels are constrained to equality). Here, no equality constraint is added.

Model:

$\%$ OVERALL\%

MODEL C1:

$\%$ c1\#1\%

[UCL1 UCR1 UCW1](ma1-ma3); UCL1 UCR1 UCW1(va1-va3);

$\%$ c1\#2\%

[UCL1 UCR1 UCW1](ma4-ma6); UCL1 UCR1 UCW1(va4-va6);

$\%$ c1\#3\%

[UCL1 UCR1 UCW1](ma7-ma9); UCL1 UCR1 UCW1(va7-va9);

$\%$ c1\#4\%

[UCL1 UCR1 UCW1](ma10-ma12); UCL1 UCR1 UCW1(va10-va12);

MODEL C2:

$\%$ c2\#1\%

[UCL2 UCR2 UCW2](mb1-mb3); UCL2 UCR2 UCW2(vb1-vb3);

$\%$ c2\#2\%

[UCL2 UCR2 UCW2](mb4-mb6); UCL2 UCR2 UCW2(vb4-vb6);

$\%$ c2\#3\%

[UCL2 UCR2 UCW2](mb7-mb9); UCL2 UCR2 UCW2(vb7-vb9);

$\%$ c2\#4\%

[UCL2 UCR2 UCW2](mb10-mb12); UCL2 UCR2 UCW2(vb10-vb12);

MODEL C3:

$\%$ c3\#1\%

[UCL3 UCR3 UCW3](mc1-mc3); UCL3 UCR3 UCW3 (vc1-vc3);

$\%$ c $3 \# 2 \%$

[UCL3 UCR3 UCW3](mc4-mc6); UCL3 UCR3 UCW3 (vc4-vc6);

$\%$ c3\#3\%

[UCL3 UCR3 UCW3](mc7-mc9); UCL3 UCR3 UCW3 (vc7-vc9);

$\%$ c $3 \# 4 \%$

[UCL3 UCR3 UCW4](mc10-mc12); UCL4 UCR4 UCW4(vc10-vc12);

OUTPUT: STDYX SAMPSTAT CINTERVAL MODINDICES (10) SVALUES

RESIDUAL TECH1 TECH7 TECH11 TECH13 TECH14; 
Mplus Input to Estimate a Structural Similarity Model for a Longitudinal Latent Profile Analysis ! Annotations only focus on functions not previously defined.

DATA:

FILE IS Unionprofile.dat;

VARIABLE:

NAMES = ID UCL1 UCR1 UCW1 UCL2 UCR2 UCW2 UCL3 UCR3 UCW3

BIGL1 UNINST1 BIGL2 UNINST2 BIGL3 UNINST3 SFA1 SQUMR1 SFA2 SQUMR2 SFA3 SQUMR3

UCBI2 UCBO2 UCBI3 UCBO3;

USEVARIABLES = UCL1 UCR1 UCW1 UCL2 UCR2 UCW2 UCL3 UCR3 UCW3;

IDVARIABLE = ID;

CLASSES = c1 (4) c2 (4) c3 (4);

Analysis:

TYPE = MIXTURE ;

ESTIMATOR = MLR;

process $=3$;

STARTS $=10000$ 500; STITERATIONS = 1000;

MODEL:

$\%$ OVERALL\%

! Labels in bold indicate newly imposed equality constraints on means across time waves.

MODEL C1:

$\%$ c1\#1\%

[UCL1 UCR1 UCW1](ma1-ma3); UCL1 UCR1 UCW1(va1-va3);

$\%$ c1\#2\%

[UCL1 UCR1 UCW1](ma4-ma6); UCL1 UCR1 UCW1(va4-va6);

$\%$ c1\#3\%

[UCL1 UCR1 UCW1](ma7-ma9); UCL1 UCR1 UCW1(va7-va9);

$\%$ c1\#4\%

[UCL1 UCR1 UCW1](ma10-ma12); UCL1 UCR1 UCW1(va10-va12);

MODEL C2:

$\%$ c2\#1\%

[UCL2 UCR2 UCW2](ma1-ma3); UCL2 UCR2 UCW2(vb1-vb3);

$\%$ c2\#2\%

[UCL2 UCR2 UCW2](ma4-ma6); UCL2 UCR2 UCW2(vb4-vb6);

$\%$ c2\#3\%

[UCL2 UCR2 UCW2](ma7-ma9); UCL2 UCR2 UCW2(vb7-vb9);

$\%$ c2\#4\%

[UCL2 UCR2 UCW2](ma10-ma12); UCL2 UCR2 UCW2(vb10-vb12);

MODEL C3:

$\%$ c $3 \# 1 \%$

[UCL3 UCR3 UCW3](ma1-ma3); UCL3 UCR3 UCW3(vc1-vc3);

$\%$ c3\#2\%

[UCL3 UCR3 UCW3](ma4-ma6); UCL3 UCR3 UCW3(vc4-vc6);

$\%$ c3\#3\%

[UCL3 UCR3 UCW3](ma7-ma9); UCL3 UCR3 UCW3(vc7-vc9);

$\%$ c3\#4\%

[UCL3 UCR3 UCW3](ma10-ma12); UCL3 UCR3 UCW3(vc10-vc12);

OUTPUT: STDYX SAMPSTAT CINTERVAL MODINDICES (10) SVALUES

RESIDUAL TECH1 TECH7 TECH11 TECH13 TECH14; 
Mplus Input to Estimate a Dispersion Similarity Model for a Longitudinal Latent Profile Analysis ! Annotations only focus on functions not previously defined.

DATA:

FILE IS Unionprofile.dat;

VARIABLE:

NAMES = ID UCL1 UCR1 UCW1 UCL2 UCR2 UCW2 UCL3 UCR3 UCW3

BIGL1 UNINST1 BIGL2 UNINST2 BIGL3 UNINST3 SFA1 SQUMR1 SFA2 SQUMR2 SFA3 SQUMR3

UCBI2 UCBO2 UCBI3 UCBO3;

USEVARIABLES = UCL1 UCR1 UCW1 UCL2 UCR2 UCW2 UCL3 UCR3 UCW3;

IDVARIABLE = ID;

CLASSES = c1 (4) c2 (4) c3 (4);

Analysis:

TYPE = MIXTURE ;

ESTIMATOR = MLR;

process $=3$;

STARTS = 10000 500; STITERATIONS = 1000;

MODEL:

$\%$ OVERALL\%

! Labels in bold indicate newly imposed equality constraints on variances across time waves.

MODEL C1:

$\%$ c1\#1\%

[UCL1 UCR1 UCW1](ma1-ma3); UCL1 UCR1 UCW1(va1-va3);

$\%$ c1\#2\%

[UCL1 UCR1 UCW1](ma4-ma6); UCL1 UCR1 UCW1(va4-va6);

$\%$ c1\#3\%

[UCL1 UCR1 UCW1](ma7-ma9); UCL1 UCR1 UCW1(va7-va9);

$\%$ c1\#4\%

[UCL1 UCR1 UCW1](ma10-ma12); UCL1 UCR1 UCW1(va10-va12);

MODEL C2:

$\%$ c2\#1\%

[UCL2 UCR2 UCW2](ma1-ma3); UCL2 UCR2 UCW2(va1-va3);

$\%$ c2\#2\%

[UCL2 UCR2 UCW2](ma4-ma6); UCL2 UCR2 UCW2(va4-va6);

$\%$ c2\#3\%

[UCL2 UCR2 UCW2](ma7-ma9); UCL2 UCR2 UCW2(va7-va9);

$\%$ c2\#4\%

[UCL2 UCR2 UCW2](ma10-ma12); UCL2 UCR2 UCW2(va10-va12);

MODEL C3:

$\%$ c $3 \# 1 \%$

[UCL3 UCR3 UCW3](ma1-ma3); UCL3 UCR3 UCW3(va1-va3);

$\%$ c3\#2\%

[UCL3 UCR3 UCW3](ma4-ma6); UCL3 UCR3 UCW3(va4-va6);

$\%$ c3\#3\%

[UCL3 UCR3 UCW3](ma7-ma9); UCL3 UCR3 UCW3(va7-va9);

$\%$ c3\#4\%

[UCL3 UCR3 UCW3](ma10-ma12); UCL3 UCR3 UCW3(va10-va12);

OUTPUT: STDYX SAMPSTAT CINTERVAL MODINDICES (10) SVALUES

RESIDUAL TECH1 TECH7 TECH11 TECH13 TECH14; 
Mplus Input to Estimate a Partial Dispersion Similarity Model for a Longitudinal Latent Profile Analysis

! Annotations only focus on functions not previously defined.

DATA:

FILE IS Unionprofile.dat;

VARIABLE:

NAMES = ID UCL1 UCR1 UCW1 UCL2 UCR2 UCW2 UCL3 UCR3 UCW3

BIGL1 UNINST1 BIGL2 UNINST2 BIGL3 UNINST3 SFA1 SQUMR1 SFA2 SQUMR2 SFA3 SQUMR3

UCBI2 UCBO2 UCBI3 UCBO3;

USEVARIABLES = UCL1 UCR1 UCW1 UCL2 UCR2 UCW2 UCL3 UCR3 UCW3;

IDVARIABLE $=$ ID;

CLASSES = c1 (4) c2 (4) c3 (4);

Analysis:

TYPE $=$ MIXTURE ;

ESTIMATOR $=$ MLR;

process $=3$;

STARTS $=10000$ 500; STITERATIONS $=1000 ;$

MODEL:

$\%$ OVERALL\%

! Labels in bold indicate that equality constraints on Wave 3 variances have been taken out.

MODEL C1:

$\% \mathrm{c} 1 \# 1 \%$

[UCL1 UCR1 UCW1](ma1-ma3); UCL1 UCR1 UCW1(va1-va3);

$\%$ c1\#2\%

[UCL1 UCR1 UCW1](ma4-ma6); UCL1 UCR1 UCW1(va4-va6);

$\%$ c1\#3\%

[UCL1 UCR1 UCW1](ma7-ma9); UCL1 UCR1 UCW1(va7-va9);

$\%$ c1\#4\%

[UCL1 UCR1 UCW1](ma10-ma12); UCL1 UCR1 UCW1(va10-va12);

MODEL C2:

$\%$ c2\#1\%

[UCL2 UCR2 UCW2](ma1-ma3); UCL2 UCR2 UCW2(va1-va3);

$\%$ c2\#2\%

[UCL2 UCR2 UCW2](ma4-ma6); UCL2 UCR2 UCW2(va4-va6);

$\%$ c2\#3\%

[UCL2 UCR2 UCW2](ma7-ma9); UCL2 UCR2 UCW2(va7-va9);

$\%$ c2\#4\%

[UCL2 UCR2 UCW2](ma10-ma12); UCL2 UCR2 UCW2(va10-va12);

MODEL C3:

$\%$ c3\#1\%

[UCL3 UCR3 UCW3](ma1-ma3); UCL3 UCR3 UCW3(vc1-vc3);

$\%$ c3\#2\%

[UCL3 UCR3 UCW3](ma4-ma6); UCL3 UCR3 UCW3(vc4-vc6);

$\%$ c3\#3\%

[UCL3 UCR3 UCW3](ma7-ma9); UCL3 UCR3 UCW3(vc7-vc9);

$\%$ c3\#4\%

[UCL3 UCR3 UCW3](ma10-ma12); UCL3 UCR3 UCW3(va10-va12);

OUTPUT: STDYX SAMPSTAT CINTERVAL MODINDICES (10) SVALUES

RESIDUAL TECH1 TECH7 TECH11 TECH13 TECH14; 
Mplus Input to Estimate a Distribution Similarity Model for a Longitudinal Latent Profile Analysis

! Annotations only focus on functions not previously defined.

! This model builds from the model of partial dispersion similarity

DATA:

FILE IS Unionprofile.dat;

VARIABLE:

NAMES = ID UCL1 UCR1 UCW1 UCL2 UCR2 UCW2 UCL3 UCR3 UCW3

BIGL1 UNINST1 BIGL2 UNINST2 BIGL3 UNINST3 SFA1 SQUMR1 SFA2 SQUMR2 SFA3 SQUMR3

UCBI2 UCBO2 UCBI3 UCBO3;

USEVARIABLES = UCL1 UCR1 UCW1 UCL2 UCR2 UCW2 UCL3 UCR3 UCW3;

IDVARIABLE = ID;

CLASSES = c1 (4) c2 (4) c3 (4);

Analysis:

TYPE = MIXTURE ;

ESTIMATOR = MLR;

process $=3$;

STARTS = 10000 500; STITERATIONS = 1000;

! The additions in bold (in \% Overall\%) constrain class sizes to be equivalent across time waves.

$! c 1, c 2, c 3$ refer to the various latent profile variables (for each time waves), whereas \#1, \#2, \#3

! refer to the specific profile in this model. One less statement than the number of profiles is needed.

MODEL:

\%OVERALL\%

[c1\#1] (p1); [c1\#2] (p2); [c1\#3] (p3);

[c2\#1] (p1); [c2\#2] (p2); [c2\#3] (p3);

[c3\#1] (p1); [c3\#2] (p2); [c3\#3] (p3);

MODEL C1:

$\%$ c1\#1\%

[UCL1 UCR1 UCW1](ma1-ma3); UCL1 UCR1 UCW1(va1-va3);

$\%$ c1\#2\%

[UCL1 UCR1 UCW1](ma4-ma6); UCL1 UCR1 UCW1(va4-va6);

$\%$ c1\#3\%

[UCL1 UCR1 UCW1](ma7-ma9); UCL1 UCR1 UCW1(va7-va9);

$\%$ c1\#4\%

[UCL1 UCR1 UCW1](ma10-ma12); UCL1 UCR1 UCW1(va10-va12);

MODEL C2:

$\%$ c2\#1\%

[UCL2 UCR2 UCW2](ma1-ma3); UCL2 UCR2 UCW2(va1-va3);

$\%$ c $2 \# 2 \%$

[UCL2 UCR2 UCW2](ma4-ma6); UCL2 UCR2 UCW2(va4-va6);

$\%$ c2\#3\%

[UCL2 UCR2 UCW2](ma7-ma9); UCL2 UCR2 UCW2(va7-va9);

$\%$ c2\#4\%

[UCL2 UCR2 UCW2](ma10-ma12); UCL2 UCR2 UCW2(va10-va12);

MODEL C3:

$\%$ c3\#1\%

[UCL3 UCR3 UCW3](ma1-ma3); UCL3 UCR3 UCW3(vc1-vc3);

$\%$ c $3 \# 2 \%$

[UCL3 UCR3 UCW3](ma4-ma6); UCL3 UCR3 UCW3(vc4-vc6);

$\%$ c3\#3\%

[UCL3 UCR3 UCW3](ma7-ma9); UCL3 UCR3 UCW3(vc7-vc9);

$\%$ c $3 \# 4 \%$

[UCL3 UCR3 UCW3](ma10-ma12); UCL3 UCR3 UCW3(va10-va12);

OUTPUT: STDYX SAMPSTAT CINTERVAL MODINDICES (10) SVALUES

RESIDUAL TECH1 TECH7 TECH11 TECH13 TECH14; 
Mplus Input to Convert the Final Partial Dispersion Similarity Model to the Latent Transition Analysis Context

! Annotations only focus on functions not previously defined.

DATA:

FILE IS Unionprofile.dat;

VARIABLE:

NAMES = ID UCL1 UCR1 UCW1 UCL2 UCR2 UCW2 UCL3 UCR3 UCW3

BIGL1 UNINST1 BIGL2 UNINST2 BIGL3 UNINST3 SFA1 SQUMR1 SFA2 SQUMR2 SFA3 SQUMR3

UCBI2 UCBO2 UCBI3 UCBO3;

USEVARIABLES = UCL1 UCR1 UCW1 UCL2 UCR2 UCW2 UCL3 UCR3 UCW3;

IDVARIABLE = ID;

CLASSES = c1 (4) c2 (4) c3 (4);

Analysis:

TYPE = MIXTURE ;

ESTIMATOR = MLR;

process $=3$;

STARTS = 10000 500; STITERATIONS = 1000;

MODEL:

$\%$ OVERALL $\%$

! The line of code below is sufficient to request a complete LTA model, with profile

! membership at Time t allowed to predict profile membership at Time $t+1$.

! The situation would be more complex if the model of distributional similarity had

$!$ was retained. For a detailed presentation of the approach to adopt in this specific

! circumstance, see Morin and Litalien (2017: http://smslabstats.weebly.com/webnotes.html)

c2 on c1; c3 on c2;

MODEL C1:

$\%$ c1\#1\%

[UCL1 UCR1 UCW1](ma1-ma3); UCL1 UCR1 UCW1(va1-va3);

$\%$ c1\#2\%

[UCL1 UCR1 UCW1](ma4-ma6); UCL1 UCR1 UCW1(va4-va6);

$\% \mathrm{c} 1 \# 3 \%$

[UCL1 UCR1 UCW1](ma7-ma9); UCL1 UCR1 UCW1(va7-va9);

$\%$ c1\#4\%

[UCL1 UCR1 UCW1](ma10-ma12); UCL1 UCR1 UCW1(va10-va12);

MODEL C2:

$\%$ c2\#1\%

[UCL2 UCR2 UCW2](ma1-ma3); UCL2 UCR2 UCW2(va1-va3);

$\%$ c2\#2\%

[UCL2 UCR2 UCW2](ma4-ma6); UCL2 UCR2 UCW2(va4-va6);

$\%$ c2\#3\%

[UCL2 UCR2 UCW2](ma7-ma9); UCL2 UCR2 UCW2(va7-va9);

$\%$ c2\#4\%

[UCL2 UCR2 UCW2](ma10-ma12); UCL2 UCR2 UCW2(va10-va12);

MODEL C3:

$\%$ c3\#1\%

[UCL3 UCR3 UCW3](ma1-ma3); UCL3 UCR3 UCW3(vc1-vc3);

$\%$ c $3 \# 2 \%$

[UCL3 UCR3 UCW3](ma4-ma6); UCL3 UCR3 UCW3(vc4-vc6);

$\%$ c3\#3\%

[UCL3 UCR3 UCW3](ma7-ma9); UCL3 UCR3 UCW3(vc7-vc9);

$\%$ c3\#4\%

[UCL3 UCR3 UCW3](ma10-ma12); UCL3 UCR3 UCW3(va10-va12);

OUTPUT: STDYX SAMPSTAT CINTERVAL MODINDICES (10) SVALUES

RESIDUAL TECH1 TECH7 TECH11 TECH13 TECH14; 
Mplus Input to Estimate a Latent Transition Analysis with Predictors Freely Estimated Across Time Waves and Profiles.

! This model builds from the model of partial dispersion similarity

! To ensure stability, starts values from the previously most similar solution should be used.

DATA: FILE IS Unionprofile.dat;

VARIABLE:

NAMES = ID UCL1 UCR1 UCW1 UCL2 UCR2 UCW2 UCL3 UCR3 UCW3 BIGL1 UNINST1 BIGL2 UNINST2 BIGL3 UNINST3 SFA1 SQUMR1 SFA2 SQUMR2 SFA3 SQUMR3 UCBI2 UCBO2 UCBI3 UCBO3;

USEVARIABLES = UCL1 UCR1 UCW1 UCL2 UCR2 UCW2 UCL3 UCR3 UCW3 BIGL1 UNINST1 SFA1 SQUMR1 BIGL2 UNINST2 SFA2 SQUMR2 BIGL3 UNINST3 SFA3 SQUMR3;

IDVARIABLE = ID;

CLASSES = c1 (4) c2 (4) c3 (4);

Analysis:

TYPE = MIXTURE; ESTIMATOR = MLR; process = 3; STARTS = 10000 500; STITERATIONS = 1000;

MODEL:

$\%$ OVERALL\%

c2 on $\mathrm{c} 1 ; \mathrm{c} 3$ on $\mathrm{c} 2$;

! The following statements indicate that class membership at each specific time wave is predicted by

! the predictors. The prediction of $C 2$ and $C 3$ is also allowed to be profile specific.

C1 ON BIGL1 UNINST1 SFA1 SQUMR1;

C2 on BIGL2 UNINST2 SFA2 SQUMR2;

C3 on BIGL3 UNINST3 SFA3 SQUMR3;

MODEL C1:

$\%$ c1\#1\%

[UCL1 UCR1 UCW1](ma1-ma3); UCL1 UCR1 UCW1(va1-va3);

C2 on BIGL2 UNINST2 SFA2 SQUMR2;

$\%$ c1\#2\%

[UCL1 UCR1 UCW1](ma4-ma6); UCL1 UCR1 UCW1(va4-va6);

C2 on BIGL2 UNINST2 SFA2 SQUMR2;

$\%$ c1\#3\%

[UCL1 UCR1 UCW1](ma7-ma9); UCL1 UCR1 UCW1(va7-va9);

C2 on BIGL2 UNINST2 SFA2 SQUMR2;

$\%$ c1\#4\%

[UCL1 UCR1 UCW1](ma10-ma12); UCL1 UCR1 UCW1(va10-va12);

C2 on BIGL2 UNINST2 SFA2 SQUMR2;

MODEL C2:

$\%$ c $2 \# 1 \%$

[UCL2 UCR2 UCW2](ma1-ma3); UCL2 UCR2 UCW2(va1-va3);

C3 on BIGL3 UNINST3 SFA3 SQUMR3;

$\%$ c2\#2\%

[UCL2 UCR2 UCW2](ma4-ma6); UCL2 UCR2 UCW2(va4-va6);

C3 on BIGL3 UNINST3 SFA3 SQUMR3;

$\%$ c2\#3\%

[UCL2 UCR2 UCW2](ma7-ma9); UCL2 UCR2 UCW2(va7-va9);

C3 on BIGL3 UNINST3 SFA3 SQUMR3;

$\%$ c2\#4\%

[UCL2 UCR2 UCW2](ma10-ma12); UCL2 UCR2 UCW2(va10-va12);

C3 on BIGL3 UNINST3 SFA3 SQUMR3;

MODEL C3:

$\%$ c3\#1\%

[UCL3 UCR3 UCW3](ma1-ma3); UCL3 UCR3 UCW3(vc1-vc3);

$\%$ c3\#2\%

[UCL3 UCR3 UCW3](ma4-ma6); UCL3 UCR3 UCW3(vc4-vc6);

$\%$ c3\#3\%

[UCL3 UCR3 UCW3](ma7-ma9); UCL3 UCR3 UCW3(vc7-vc9);

$\%$ c3\#4\%

[UCL3 UCR3 UCW3](ma10-ma12); UCL3 UCR3 UCW3(va10-va12);

OUTPUT: STDYX SAMPSTAT CINTERVAL MODINDICES (10) SVALUES RESIDUAL TECH1 TECH7 TECH11 TECH13 TECH14; 
Mplus Input to Estimate a Latent Transition Analysis with Predictors Freely Estimated Across Time Waves.

! Annotations only focus on functions not previously defined.

! This model builds from the model of partial dispersion similarity

! To ensure stability, starts values from the previously most similar solution should be used.

DATA: FILE IS Unionprofile.dat;

VARIABLE:

NAMES = ID UCL1 UCR1 UCW1 UCL2 UCR2 UCW2 UCL3 UCR3 UCW3

BIGL1 UNINST1 BIGL2 UNINST2 BIGL3 UNINST3 SFA1 SQUMR1 SFA2 SQUMR2 SFA3 SQUMR3

UCBI2 UCBO2 UCBI3 UCBO3;

USEVARIABLES = UCL1 UCR1 UCW1 UCL2 UCR2 UCW2 UCL3 UCR3 UCW3

BIGL1 UNINST1 SFA1 SQUMR1 BIGL2 UNINST2 SFA2 SQUMR2

BIGL3 UNINST3 SFA3 SQUMR3;

IDVARIABLE = ID;

CLASSES = c1 (4) c2 (4) c3 (4);

Analysis:

TYPE = MIXTURE ; ESTIMATOR = MLR; process = 3;

STARTS = 10000 500; STITERATIONS = 1000;

MODEL:

\%OVERALL\%

c2 on $\mathrm{c} 1$; $\mathrm{c} 3$ on $\mathrm{c} 2$;

! The following statements indicate that class membership at each specific time wave is predicted by

! the predictors.

C1 ON BIGL1 UNINST1 SFA1 SQUMR1;

C2 on BIGL2 UNINST2 SFA2 SQUMR2;

C3 on BIGL3 UNINST3 SFA3 SQUMR3;

MODEL C1:

$\%$ c1\#1\%

[UCL1 UCR1 UCW1](ma1-ma3); UCL1 UCR1 UCW1(va1-va3);

$\%$ c1\#2\%

[UCL1 UCR1 UCW1](ma4-ma6); UCL1 UCR1 UCW1(va4-va6);

$\% \mathrm{c} 1 \# 3 \%$

[UCL1 UCR1 UCW1](ma7-ma9); UCL1 UCR1 UCW1(va7-va9);

$\%$ c1\#4\%

[UCL1 UCR1 UCW1](ma10-ma12); UCL1 UCR1 UCW1(va10-va12);

MODEL C2:

$\%$ c2\#1\%

[UCL2 UCR2 UCW2](ma1-ma3); UCL2 UCR2 UCW2(va1-va3);

$\%$ c $2 \# 2 \%$

[UCL2 UCR2 UCW2](ma4-ma6); UCL2 UCR2 UCW2(va4-va6);

$\%$ c2\#3\%

[UCL2 UCR2 UCW2](ma7-ma9); UCL2 UCR2 UCW2(va7-va9);

$\%$ c2\#4\%

[UCL2 UCR2 UCW2](ma10-ma12); UCL2 UCR2 UCW2(va10-va12);

MODEL C3:

$\%$ c $3 \# 1 \%$

[UCL3 UCR3 UCW3](ma1-ma3); UCL3 UCR3 UCW3(vc1-vc3);

$\%$ c $3 \# 2 \%$

[UCL3 UCR3 UCW3](ma4-ma6); UCL3 UCR3 UCW3(vc4-vc6);

$\%$ c3\#3\%

[UCL3 UCR3 UCW3](ma7-ma9); UCL3 UCR3 UCW3(vc7-vc9);

$\%$ c3\#4\%

[UCL3 UCR3 UCW3](ma10-ma12); UCL3 UCR3 UCW3(va10-va12);

OUTPUT: STDYX SAMPSTAT CINTERVAL MODINDICES (10) SVALUES

RESIDUAL TECH1 TECH7 TECH11 TECH13 TECH14; 
Mplus Input to Estimate a Predictive Similarity Latent Transition Analysis

! This model builds from the model of partial dispersion similarity

! To ensure stability, starts values from the previously most similar solution should be used.

DATA: FILE IS Unionprofile.dat;

VARIABLE:

NAMES = ID UCL1 UCR1 UCW1 UCL2 UCR2 UCW2 UCL3 UCR3 UCW3 BIGL1 UNINST1 BIGL2 UNINST2 BIGL3 UNINST3 SFA1 SQUMR1 SFA2 SQUMR2 SFA3 SQUMR3 UCBI2 UCBO2 UCBI3 UCBO3;

USEVARIABLES = UCL1 UCR1 UCW1 UCL2 UCR2 UCW2 UCL3 UCR3 UCW3 BIGL1 UNINST1 SFA1 SQUMR1 BIGL2 UNINST2 SFA2 SQUMR2 BIGL3 UNINST3 SFA3 SQUMR3;

IDVARIABLE = ID;

CLASSES = c1 (4) c2 (4) c3 (4);

Analysis:

TYPE $=$ MIXTURE $;$ ESTIMATOR $=$ MLR; process $=3 ;$ STARTS $=10000$ 500; STITERATIONS = 1000;

MODEL:

$\%$ OVERALL $\%$

c2 on $\mathrm{c} 1$; $\mathrm{c} 3$ on $\mathrm{c} 2$;

! The following statements constrain the predictions to be equal across time waves (one less label

! than profiles)

C1 ON BIGL1(bi1-bi3);

C1 on UNINST1(un1-un3);

C1 on SFA1(sf1-sf3);

C1 on SQUMR1(sq1-sq3);

C2 ON BIGL2(bi1-bi3);

C2 on UNINST2(un1-un3);

C2 on SFA2(sf1-sf3);

C2 on SQUMR2(sq1-sq3);

C3 ON BIGL3(bi1-bi3);

C3 on UNINST3(un1-un3);

C3 on SFA3(sf1-sf3);

C3 on SQUMR3(sq1-sq3);

MODEL C1:

$\%$ c1\#1\%

[UCL1 UCR1 UCW1](ma1-ma3); UCL1 UCR1 UCW1(va1-va3);

$\%$ c1\#2\%

[UCL1 UCR1 UCW1](ma4-ma6); UCL1 UCR1 UCW1(va4-va6);

$\%$ c1\#3\%

[UCL1 UCR1 UCW1](ma7-ma9); UCL1 UCR1 UCW1(va7-va9);

$\%$ c1\#4\%

[UCL1 UCR1 UCW1](ma10-ma12); UCL1 UCR1 UCW1(va10-va12);

MODEL C2:

$\%$ c $2 \# 1 \%$

[UCL2 UCR2 UCW2](ma1-ma3); UCL2 UCR2 UCW2(va1-va3);

$\%$ c2\#2\%

[UCL2 UCR2 UCW2](ma4-ma6); UCL2 UCR2 UCW2(va4-va6);

$\%$ c2\#3\%

[UCL2 UCR2 UCW2](ma7-ma9); UCL2 UCR2 UCW2(va7-va9);

$\%$ c2\#4\%

[UCL2 UCR2 UCW2](ma10-ma12); UCL2 UCR2 UCW2(va10-va12);

MODEL C3:

$\%$ c3\#1\%

[UCL3 UCR3 UCW3](ma1-ma3); UCL3 UCR3 UCW3(vc1-vc3);

$\%$ c3\#2\%

[UCL3 UCR3 UCW3](ma4-ma6); UCL3 UCR3 UCW3(vc4-vc6);

$\%$ c3\#3\%

[UCL3 UCR3 UCW3](ma7-ma9); UCL3 UCR3 UCW3(vc7-vc9);

$\%$ c3\#4\%

[UCL3 UCR3 UCW3](ma10-ma12); UCL3 UCR3 UCW3(va10-va12);

OUTPUT: STDYX SAMPSTAT CINTERVAL MODINDICES (10) SVALUES

RESIDUAL TECH1 TECH7 TECH11 TECH13 TECH14; 
Mplus Input to Estimate a Latent Transition Analysis with Outcomes Levels Freely Estimated Across Time Waves

! Annotations only focus on functions not previously defined.

! This model builds from the model of partial dispersion similarity

! To ensure stability, starts values from the previously most similar solution should be used.

DATA:

FILE IS Unionprofile.dat;

VARIABLE:

NAMES = ID UCL1 UCR1 UCW1 UCL2 UCR2 UCW2 UCL3 UCR3 UCW3

BIGL1 UNINST1 BIGL2 UNINST2 BIGL3 UNINST3 SFA1 SQUMR1 SFA2 SQUMR2 SFA3 SQUMR3

UCBI2 UCBO2 UCBI3 UCBO3;

USEVARIABLES = UCL1 UCR1 UCW1 UCL2 UCR2 UCW2 UCL3 UCR3 UCW3

UCBI2 UCBO2 UCBI2 UCBO3;

IDVARIABLE = ID;

CLASSES = c1 (4) c2 (4) c3 (4);

Analysis:

TYPE = MIXTURE ;

ESTIMATOR = MLR;

process $=3$;

STARTS = 10000 500; STITERATIONS = 1000;

! The additions in bold request the free estimation of the outcomes means in each profile

! Remember that outcomes are only assessed at Waves 2 and 3.

MODEL:

\%OVERALL\%

c2 on $\mathrm{c} 1 ; \mathrm{c} 3$ on $\mathrm{c} 2$;

MODEL C1:

$\%$ c1\#1\%

[UCL1 UCR1 UCW1](ma1-ma3); UCL1 UCR1 UCW1(va1-va3);

$\%$ c1\#2\%

[UCL1 UCR1 UCW1](ma4-ma6); UCL1 UCR1 UCW1(va4-va6);

$\% \mathrm{c} 1 \# 3 \%$

[UCL1 UCR1 UCW1](ma7-ma9); UCL1 UCR1 UCW1(va7-va9);

$\%$ c1\#4\%

[UCL1 UCR1 UCW1](ma10-ma12); UCL1 UCR1 UCW1(va10-va12);

MODEL C2:

$\%$ c2\#1\%

[UCL2 UCR2 UCW2](ma1-ma3); UCL2 UCR2 UCW2(va1-va3);

[UCBI2](aa1); [UCBO2](ab1);

$\%$ c2\#2\%

[UCL2 UCR2 UCW2](ma4-ma6); UCL2 UCR2 UCW2(va4-va6);

[UCBI2](aa2); [UCBO2](ab2);

$\%$ c2\#3\%

[UCL2 UCR2 UCW2](ma7-ma9); UCL2 UCR2 UCW2(va7-va9);

[UCBI2](aa3); [UCBO2](ab3);

$\%$ c2\#4\%

[UCL2 UCR2 UCW2](ma10-ma12); UCL2 UCR2 UCW2(va10-va12);

[UCBI2](aa4); [UCBO2](ab4);

MODEL C3:

$\%$ c3\#1\%

[UCL3 UCR3 UCW3](ma1-ma3); UCL3 UCR3 UCW3(vc1-vc3);

[UCBI3](ba1); [UCBO3](bb1);

$\%$ c $3 \# 2 \%$

[UCL3 UCR3 UCW3](ma4-ma6); UCL3 UCR3 UCW3(vc4-vc6);

[UCBI3](ba2); [UCBO3](bb2);

$\%$ c3\#3\%

[UCL3 UCR3 UCW3](ma7-ma9); UCL3 UCR3 UCW3(vc7-vc9);

[UCBI3](ba3); [UCBO3](bb3);

$\%$ c3\#4\%

[UCL3 UCR3 UCW3](ma10-ma12); UCL3 UCR3 UCW3(va10-va12);

[UCBI3](ba4); [UCBO3](bb4); 
! The model constraint function uses the labels used with the outcomes to request mean level comparisons on the outcomes across profiles.

MODEL CONSTRAINT:

NEW (yaa12); yaa12 = aa1-aa2;

NEW (yaa13); yaa13 = aa1-aa3;

NEW (yaa14); yaa14 = aa1-aa4;

NEW (yaa23); yaa23 = aa2-aa3;

NEW (yaa24); yaa24 = aa2-aa4;

NEW (yaa34); yaa34 = aa3-aa4;

NEW (yab12); yab12 = ab1-ab2;

NEW (yab13); yab13 = ab1-ab3;

NEW (yab14); yab14 = ab1-ab4;

NEW (yab23); yab23 = ab2-ab3;

NEW (yab24); yab24 = ab2-ab4;

NEW (yab34); yab34 = ab3-ab4;

NEW (yba12); yba12 = ba1-ba2;

NEW (yba13); yba13 = ba1-ba3;

NEW (yba14); yba14 = ba1-ba4;

NEW (yba23); yba23 = ba2-ba3;

NEW (yba24); yba24 = ba2-ba4;

NEW (yba34); yba34 = ba3-ba4;

NEW (ybb12); ybb12 = bb1-bb2;

NEW (ybb13); ybb13 = bb1-bb3;

NEW (ybb14); ybb14 = bb1-bb4;

NEW (ybb23); ybb23 = bb2-bb3;

NEW (ybb24); ybb24 = bb2-bb4;

NEW (ybb34); ybb34 = bb3-bb4;

OUTPUT: STDYX SAMPSTAT CINTERVAL MODINDICES (10) SVALUES

RESIDUAL TECH1 TECH7 TECH11 TECH13 TECH14; 
Mplus Input to Estimate an Explanatory Similarity Latent Transition Analysis

! Annotations only focus on functions not previously defined.

! This model builds from the model of partial dispersion similarity

! To ensure stability, starts values from the previously most similar solution should be used.

DATA:

FILE IS Unionprofile.dat;

VARIABLE:

NAMES = ID UCL1 UCR1 UCW1 UCL2 UCR2 UCW2 UCL3 UCR3 UCW3

BIGL1 UNINST1 BIGL2 UNINST2 BIGL3 UNINST3 SFA1 SQUMR1 SFA2 SQUMR2 SFA3 SQUMR3

UCBI2 UCBO2 UCBI3 UCBO3;

USEVARIABLES = UCL1 UCR1 UCW1 UCL2 UCR2 UCW2 UCL3 UCR3 UCW3

UCBI2 UCBO2 UCBI2 UCBO3;

IDVARIABLE = ID;

CLASSES = c1 (4) c2 (4) c3 (4);

Analysis:

TYPE = MIXTURE ;

ESTIMATOR = MLR;

process $=3$;

STARTS = 10000 500; STITERATIONS = 1000;

! The additions in bold constrain outcome levels to be equivalent across time waves.

MODEL:

$\%$ OVERALL\%

c2 on $\mathrm{c} 1 ; \mathrm{c} 3$ on $\mathrm{c} 2$;

MODEL C1:

$\%$ c1\#1\%

[UCL1 UCR1 UCW1](ma1-ma3); UCL1 UCR1 UCW1(va1-va3);

$\%$ c1\#2\%

[UCL1 UCR1 UCW1](ma4-ma6); UCL1 UCR1 UCW1(va4-va6);

$\%$ c1\#3\%

[UCL1 UCR1 UCW1](ma7-ma9); UCL1 UCR1 UCW1(va7-va9);

$\%$ c1\#4\%

[UCL1 UCR1 UCW1](ma10-ma12); UCL1 UCR1 UCW1(va10-va12);

MODEL C2:

$\%$ c2\#1\%

[UCL2 UCR2 UCW2](ma1-ma3); UCL2 UCR2 UCW2(va1-va3); [UCBI2](aa1); [UCBO2](ab1);

$\%$ c2\#2\%

[UCL2 UCR2 UCW2](ma4-ma6); UCL2 UCR2 UCW2(va4-va6);

[UCBI2](aa2); [UCBO2](ab2);

$\%$ c2\#3\%

[UCL2 UCR2 UCW2](ma7-ma9); UCL2 UCR2 UCW2(va7-va9);

[UCBI2](aa3); [UCBO2](ab3);

$\%$ c2\#4\%

[UCL2 UCR2 UCW2](ma10-ma12); UCL2 UCR2 UCW2(va10-va12);

[UCBI2](aa4); [UCBO2](ab4);

MODEL C3:

$\%$ c $3 \# 1 \%$

[UCL3 UCR3 UCW3](ma1-ma3); UCL3 UCR3 UCW3(vc1-vc3); [UCBI3](aa1); [UCBO3](ab1);

$\%$ c $3 \# 2 \%$

[UCL3 UCR3 UCW3](ma4-ma6); UCL3 UCR3 UCW3(vc4-vc6); [UCBI3](aa2); [UCBO3](ab2);

$\%$ c3\#3\%

[UCL3 UCR3 UCW3](ma7-ma9); UCL3 UCR3 UCW3(vc7-vc9);

[UCBI3] (aa3); [UCBO3](ab3);

$\%$ c3\#4\%

[UCL3 UCR3 UCW3](ma10-ma12); UCL3 UCR3 UCW3(va10-va12);

[UCBI3](aa4); [UCBO3](ab4);

! The model constraint function uses the labels used with the outcomes to request mean level comparisons on the outcomes across profiles. 
MODEL CONSTRAINT:

NEW (yaa12); yaa12 = aa1-aa2;

NEW (yaa13); yaa13 = aa1-aa3;

NEW (yaa14); yaa14 = aa1-aa4;

NEW (yaa23); yaa23 = aa2-aa3;

NEW (yaa24); yaa24 = aa2-aa4;

NEW (yaa34); yaa34 = aa3-aa4;

NEW (yab12); yab12 = ab1-ab2;

NEW (yab13); yab13 = ab1-ab3;

NEW (yab14); yab14 = ab1-ab4;

NEW (yab23); yab23 = ab2-ab3;

NEW (yab24); yab24 = ab2-ab4;

NEW (yab34); yab34 = ab3-ab4;

OUTPUT: STDYX SAMPSTAT CINTERVAL MODINDICES (10) SVALUES

RESIDUAL TECH1 TECH7 TECH11 TECH13 TECH14; 